\title{
Origin of the warm eastern tropical Atlantic SST bias in a climate model
}

\author{
E. Exarchou \\ C. Prodhomme \\ L. Brodeau \\ V. Guemas \\ F. Doblas-Reyes
}

May 23, 2017

\begin{abstract}
The substantial warm sea surface temperature bias in the eastern Tropical Atlantic reported in most CMIP5 climate simulations with various models, in particular along the coast of Namibia and Angola, remains an issue in more recent and CMIP6-ready versions of climate models such as EC-Earth. A complete and original set of experiments with EC-Earth3.1 is performed to investigate the causes and mechanisms responsible for the emergence and persistence of this bias. The fully-developed bias is studied in a historical experiment that has reached quasi-equilibrium, while retrospective prediction experiments are used to highlight the development/growth from an observed initial state. Prediction experiments are performed at both low and high resolution to assess the possible dependence of the bias on horizontal resolution. Standalone experiments with the ocean and the atmosphere components of EC-Earth are also analyzed to separate the respective contributions of the ocean and atmosphere to the development of the bias. EC-Earth3.1 exhibits a bias similar to that reported in most climate models that took part in CMIP5. The magnitude of this bias, however, is weaker than most CMIP5 models by few degrees. Increased horizontal resolution only leads to a minor reduction of the bias in EC-Earth. The warm SST bias is found to be the result of an excessive solar absorption in the ocean mixed layer, which can be linked to the excessive solar insolation due to unrealistically low cloud cover, and the absence of spatial and temporal variability of the biological productivity in the ocean component. The warm SST bias is further linked to deficient turbulent vertical mixing of cold water to the mixed layer. Our study points at a need for better representation of clouds in the vicinity of eastern boundaries in atmosphere models, and better representation of solar penetration and turbulent mixing in the ocean models in order to eliminate the Tropical Atlantic biases.
\end{abstract}

\section{Introduction}

The continuous improvement of seasonal forecasts during the past decades (Doblas-Reyes et al., 2013a,b) has benefited different socioeconomic sectors, such as insurance companies (Jewson et al., 2008; Emanuel et al., 2012) wind and hydro-electric energy companies (De Felice et al., 2015; Garcia-Morales and Dubus, 2007), the agriculture sector (DoblasReyes et al., 2006; Crane et al., 2010; Soret et al., 2016) and climate-driven disease prevention (Tompkins and di Giuseppe, 2015). In addition, recent studies have shown that 
seasonal forecasts could be successful in forecasting high impact events, such as heatwaves or tropical cyclones, a few months in advance (e.g. Caron et al., 2014; Prodhomme et al., 2015).

This improvement is the consequence of both the improvement of the physics, numerics, and sub-scale parameterizations of coupled atmosphere-ocean global circulation models (hereafter AOGCMs), as well as the increase in supercomputing capabilities which allows AOGCMs to be run at increasingly high horizontal resolution. Improvements in initialization techniques and initialization data have also played a key role in improving seasonal forecasts. However, AOGCMs still suffer from strong SST biases, i.e. they exhibit systematic SST differences with respect to observations, which affect their ability to reliably simulate climate variability and change (Knutti et al., 2006; Hourdin et al., 2013; Qu et al., 2014; Sherwood et al., 2014). These SST biases have been reported to be the consequence of different aspects such as insufficient horizontal and vertical resolution of the model grids, deficiencies in the parameterizations of subgrid-scale processes, limitations of the numerical schemes to solve the model equations (Huang et al., 2003; Stainforth et al., 2005; Brierley et al., 2008; Hawkins and Sutton, 2009; Zheng et al., 2011; Jung et al., 2012; Sakamoto et al., 2012; Maclachlan et al., 2014; Song et al., 2015). In the context of climate predictions, other aspects, such as inaccurate initial conditions (particularly in the deep ocean), and inaccurate boundary conditions (radiative forcings) have been shown to matter (Balmaseda et al., 2009; Carslaw et al., 2013). In particular, since numerical predictions are initialized with data from atmosphere and ocean reanalyses, they tend to incorporate biases already at the initialization stage. This is particularly true in the deep ocean where the lack of observations affects the quality of ocean reanalyses/reconstructions and other products (Balmaseda et al., 2013). Inconsistencies between the inherent circulation patterns of an unconstrained AOGCM and the circulation patterns of a given reanalysis system (heavily constrained by observations), can be responsible for the model drift during the simulation (Balmaseda et al., 2009). Inconsistencies between the atmosphere and ocean reanalysis used to initialize predictions, or inconsistencies between initial conditions and model dynamics, are linked to shocks at the initialization of the simulation (Zhang, 2011). Finally, since initial conditions are often available on different grids than that of the atmosphere and ocean components of the AOGCMs, further inaccuracies are introduced in the forecasts due to the remapping of fields from one grid to another. Interpolation inaccuracies can also lead to initial shocks, because interpolation can create inconsistencies between the variables.

The Tropical Atlantic is a region of particular interest in seasonal forecasting. The Tropical Atlantic variability (TAV) at different time scales strongly affects the African Monsoon (García-Serrano et al., 2013; Roehrig et al., 2013; Kucharski et al., 2008). Better understanding the TAV is essential for agriculture (Sultan et al., 2005) and fisheries (Jarre et al., 2015). The inter-annual TAV is partly driven by ENSO (Saravanan and Chang, 2000) and studies suggest that SST anomalies over the Tropical Atlantic can, in turn, affect the SST in the Pacific through a modulation of the Walker circulation (Rodríguez-Fonseca et al., 2009; Keenlyside et al., 2013; Terray et al., 2015). Most of AOGCMs used in the successive phases of the Coupled Model Intercomparison Project (CMIP) exhibit a warm SST biases over the eastern Tropical Atlantic (e.g. Huang et al., 2007; Richter and Xie, 2008; Toniazzo and Woolnough, 2013; Vannière et al., 2013; Ma et al., 2014; Voldoire et al., 2014; Chowdary et al., 2016; Richter, 2015; Small et al., 2015). The eastern Trop- 
ical Atlantic warm bias (ETAWB hereafter) has been partly explained by the unrealistic representation coastal upwelling, in particular due to insufficient vertical advection in ocean components and underestimated alongshore wind speed in atmosphere components in some AOGCMs (Large and Danabasoglu, 2006; Richter and Xie, 2008; Toniazzo and Woolnough, 2013). The underestimation of the surface wind speed over the eastern boundary coastal upwelling regions is a feature common to several AGCMs and has been linked to unrealistic precipitations. This wind-precipitation link tends to be amplified in coupled models (Richter and Xie, 2008; Richter, 2015).

Another issue highlighted in some climate models is the underestimation of cloud cover at coastal boundaries (e.g. Zhang et al., 2005; Wyant et al., 2006), which leads to excessive excessive solar radiation and positive SST biases (e.g. Wahl et al., 2011; Richter, 2015). These errors are linked to e.g. unresolved vertical temperature and moisture gradients and small scale turbulence due to insufficient vertical model resolution (Lenschow et al., 2000; Haman et al., 2007; Stevens et al., 2005). The ETAWB has also been linked to the wrong spatial representation of the Angola Benguela Front (ABF) (Grodsky et al., 2012; $\mathrm{Xu}$ et al., 2014a,b). The ABF forms where two coastal currents, the northward Benguela current (BC) and the southward Angola Current (AC) converge, at about $16^{\circ} \mathrm{S}$ (Lass et al., 2000). Xu et al. (2014a) report that the ABF front is typically shifted southward by few degrees of latitude in CMIP5 models. This southward displacement is associated with a weaker BC and a stronger AC. A weaker BC tends to promote the development of a warm SST bias because the BC, which flows equatorward, imports relatively cold water from southern latitudes. The enhanced AC, which flows southward and imports relatively warm water from the Equator, also promotes the warming of the surface. $\mathrm{Xu}$ et al. (2014a) partly linked the southward shift of the ABF to an unrealistic wind stress field, with weaker alongshore winds south of the $\mathrm{ABF}$ and a stronger magnitude of the negative wind stress curl north of the $\mathrm{ABF}$, which tend to weaken the $\mathrm{BC}$ and strengthen the $\mathrm{AC}$. The eastern tropical Atlantic is a region where the vertical turbulent mixing in the ocean is an important term in the total heat budget (Giordani et al., 2013), and SST biases have been shown to be sensitive to the vertical mixing parameterization used in the ocean component (Hazeleger and Haarsma, 2005).

Surface solar heating over eastern boundary regions, such as the eastern tropical Atlantic, has been shown to be balanced by heat advection through mesoscale and sub-mesoscale eddies (Colas et al., 2012). Recent modeling studies, however, suggest that surface biases in AOGCMs are not necessarilly decreased through the use of higher eddy-permitting resolution in the ocean (Patricola et al., 2012; Xu et al., 2014b; Richter, 2015).

A large variety of processes and mechanisms has been suggested up-to-date to explain the ETAWB. However, ascertaining the root cause for this bias when it is fully developed in simulations such as historical is highly challenging, because disentangling causes from feedbacks is not always straight forward. Here, we propose a different approach to identify the root cause for the ETAWB (Vannière et al., 2014). It consists in tracking the time evolution of the model error before it converges to the model bias by analyzing those errors in seasonal hindcasts that are initialized from observations. The time scales of the error growth in the drifting hindcasts hint at the mechanisms involved, and help differentiate fast (e.g. clouds, atmospheric circulation) from slow processes (e.g. ocean circulation).

The relative importance of the different processes in the mixed layer is analyzed by means 
of a detailed heat budget of the oceanic mixed layer. The role/implication of each model component (ocean and atmosphere), as well as the importance of the atmosphere-ocean coupling, in the bias development, is assessed by analyzing standalone atmosphere and ocean simulations. Finally, we explore different hypothesis by performing and analyzing additional sensitivity experiments.

The goal of our study is not only to identify the sources of the model errors and where they originate but also suggest potential strategies to tackle those biases and encourage research groups and model developers to address those issues in a common goal toward model improvement.

This paper is organized as follows. In section 2, we describe the coupled model and the set-up of our experiments. In section 3 we identify the mechanisms leading to the warm eastern tropical Atlantic SST bias in EC-Earth and we propose strategies to reduce this bias. Our conclusions are summarized in section 4.

\section{Methodology}

\subsection{EC-Earth 3.1}

We use the EC-Earth climate model version 3.1. With respect to version 2, which is described in detail in Hazeleger et al. (2012) and Sterl et al. (2012) and was used for CMIP5, the main updates and improvements in version 3.1 are:

- improved radiation scheme (Morcrette et al., 2008)

- new cloud microphysics scheme (Forbes et al., 2011)

- inclusion of a Rayleigh friction (atmosphere)

- updated stratospheric aerosol optical depth

- introduction of an advection mass fix for water species

- reduction of the ocean diffusive albedo

- more conservative exchange of continental runoff between land-atmosphere and ocean

We use EC-Earth3.1 on two different horizontal resolution configurations, which we will refer to as the high and low resolution (hereafter HR and LR), respectively.

The atmosphere component of EC-Earth3.1 is the Integrated Forecasting System (IFS), cycle $36 \mathrm{r} 4$, of the ECMWF ${ }^{1}$. IFS is a primitive equation model with fully interactive cloud and radiation physics. HR and its T511 spectral resolution, corresponds to approximately $0.35^{\circ}$ in latitude and longitude, while for LR (T255 spectral resolution) this number is about $0.7^{\circ}$. Both HR and LR use 91 vertical levels (up to $1 \mathrm{~Pa}$ ). The time step is 2700 and 900 seconds for LR and HR, respectively.

\footnotetext{
${ }^{1}$ European Centre for Medium Range Weather Forecasts
} 
The ocean component of EC-Earth3.1 is the version 3.3.1 of $\mathrm{NEMO}^{2}$ (Madec, 2008). NEMO uses the so-called ORCA025 (HR) and ORCA1 (LR) configurations, which both consist of a tri-polar grid with poles over northern North America, Siberia and Antarctica at a resolution of about 0.25 and $1^{\circ}$, respectively. The ocean resolution used in HR is sufficient to resolve mesoscale and larger sub-mesoscale eddies in the tropical region. A higher resolution, by roughly a factor 3 , is applied close to the equator in the LR configuration. 75 (HR) and 46 (LR) z-coordinates vertical levels are defined together with a partial-step representation of the bottom topography. The vertical grid thickness ranges between $1 \mathrm{~m}$ close to the surface and $200 \mathrm{~m}$ close to the bottom in the HR configuration, and between $6 \mathrm{~m}$ and $250 \mathrm{~m}$ in the LR configuration. The effects of the subgridscale processes (mainly the mesoscale eddies) are represented by an isopycnal mixing/advection parameterization as proposed by Gent and McWilliams (1990) while the vertical mixing is parameterized according to a local turbulent kinetic energy (TKE) closure scheme (Blanke and Delecluse, 1993). A bottom boundary layer scheme, similar to that of Beckmann and Döscher (1997), is used to improve the representation of dense water spreading. The Louvain-la-Neuve Sea Ice Model version 2, LIM2, (Fichefet and Maqueda, 1997; Bouillon et al., 2009) is included in NEMO, with dynamics based on Hibler (1979) and thermodynamics based on Semtner (1976). The ocean sea-ice component NEMO-LIM2 uses a time step of 1200 and 3600 seconds in HR and LE, respectively.

The atmosphere and ocean sea-ice components of EC-Earth are coupled every 3 hours with the Ocean Atmosphere Sea Ice Soil coupler version 3 (OASIS3; Valcke, 2006).

\subsection{Experimental setup}

We perform and analyze a set of ensemble seasonal hindcasts, also referred to as retrospective forecasts. The atmosphere component (IFS) is initialized with ERA-interim reanalysis data (Dee et al., 2011, hereafter ERAi), while the ocean and sea-ice components (NEMO-LIM2) are initialized with GLORYS2V1 reanalysis data (Ferry et al., 2010).

The 10 members of a given ensemble are initialized at the same date with initial atmospheric conditions (restarts) that are built to slightly differ from one another through the use of the singular vector perturbations method (Du et al., 2012). In contrast to the atmosphere, the same (unperturbed) ocean and sea-ice initial condition (GLORYS2V1) is used for all the members of a given prediction ensemble.

The hindcasts are initialized every first of May and every first of November from 1993 until 2009 included, which corresponds to the period of availability of GLORYS2v1. They are run at both high and low resolution (HR-Hind and LR-Hind, respectively) during four months (Table 1). Thus, 34 ensembles of 10 four-month-long simulations are performed. In our analysis, unless otherwise stated, it is the ensemble mean that is discussed.

To identify the respective contribution of the ocean and atmosphere components of ECEarth in the development of the SST bias, a series of ocean- and atmosphere-standalone experiments are performed using the ORCA1L46 and T255L91 configurations, respectively (hereafter referred to as LR-Ocean and LR-Atm, respectively). In these standalone experiments, the ocean and atmosphere components are forced at the surface and use the same respective setup as in coupled mode in LR-Hind experiments. Also, only 5 ensemble members are performed for LR-Ocean and LR-Atm. LR-Ocean experiments are forced

\footnotetext{
${ }^{2}$ Nucleus for European Modelling of the Ocean
} 
using the bulk approach and the DRAKKAR forcing set version 4.3 (DFS4.3 Brodeau et al., 2010), which only extends until 2006. In LR-Atm, the SST of ERAi is prescribed as the boundary condition to IFS.

Finally, HR-Histo, a coupled historical experiment using the high-resolution configuration is run from 1960 to 2000 (Table 1).

We compute the average of all the ensemble-mean predictions starting at different dates (1993-2009) as a function of the forecast time. Its difference to the observed equivalent is referred to as the forecast bias $\left(B_{\text {forecast }}(t)\right)$ for each forecast month. $B_{\text {forecast }}(t)$ is changing with time, demonstrating the presence of a model drift. While the drift approaches to zero as the model reaches equilibrium, $B_{\text {forecast }}(t)$ converges to the model bias $B_{\text {model }}$, i.e. to the bias of the simulation in equilibrium. We estimate $B_{\text {model }}(t)$ as the difference between HR-Histo and observations averaged over the period 1960-2000 for each calendar month. Finally, throughout the paper, when referring to a season of the year we implicitly use the convention of the northern hemisphere.

\subsection{Observational/reference datasets}

Various data products from various providers are used throughout our study to assess the model performance and departure from observations.

We use monthly HadISST (Rayner, 2003), daily ERAi, and daily ESA version 1 (Merchant et al., 2014) SST as reference SSTs. For ocean properties, such as potential temperature, salinity, velocities and meridional overturning streamfunction, we use ORAS4, GLORYS2V1 and SODA ocean reanalysis (Balmaseda et al., 2013; Ferry et al., 2010; Carton and Giese, 2008). We use the turbulent and longwave surface heat fluxes of the TropFlux dataset (Kumar et al., 2012), which is a corrected version of ERAi to account for observations. We use the satelite-based observed cloud cover of the ISCCP from 1984 to 2002 (Rossow et al., 1996). The 10-meter wind speed is taken from the Scatterometer Climatology of Ocean Winds (SCOW) product (Risien and Chelton, 2008, available between September 1999 and October 2009).

\section{Results}

\subsection{The eastern Tropical Atlantic warm bias in EC-Earth}

The eastern Tropical Atlantic warm bias (ETAWB) in HR-Histo (Fig 1) has spatial structure similar to other AOGCMs (Richter and Xie, 2008; Richter, 2015), but its magnitude is smaller, by typically $1^{\circ} \mathrm{C}$ or more (Richter and Xie, 2008; Wang et al., 2014; Richter, 2015).

The ETAWB is present in every calendar month. It tends to be localized in the Southern hemisphere except in January and June, when it extends in the Northern hemisphere, albeit with a smaller magnitude. Along the coast of Angola and Namibia, the ETAWB reaches $2^{\circ} \mathrm{C}$, and persists all year round. At its maximum, the spatial extent of the ETAWB spans from $20^{\circ} \mathrm{W}$ to the African coast, and from $25^{\circ} \mathrm{S}$ to $5^{\circ} \mathrm{N}$, an area comparable to the size of Europe. The ETAWB also exhibits a seasonal cycle with a minimum in February-May, and a maximum in August-November. The episodic northward extension of the ETAWB 
is associated with the absence of the eastern equatorial Atlantic cold tongue (herafter EEACT), which normally appears in early summer.

Despite seasonal variability, the ETAWB is present throughout the year, regardless of the SST dataset used as a reference (not shown). We focus on the region over which the ETAWB is the most pronounced, namely a rectangular box over the Coast of Angola (hereafter $\mathrm{CAB}$ ). $\mathrm{CAB}$ spans $5^{\circ} \mathrm{E}-12.5^{\circ} \mathrm{E}$ and $18^{\circ} \mathrm{S}-5^{\circ} \mathrm{S}$ (Fig 1 ).

The ETAWB pattern seen in HR-Histo is already visible in HR-Hind in the first forecast month, but with a smaller amplitude (Fig 2). The intra-annual variability of the forecast bias is partly a manifestation of the seasonal cycle of the bias: the weaker forecast bias in May compared to rest of the summer months is indicative of the seasonality of the bias (as seen from comparing Fig 1a-d to Fig 2a-d). The growth of the forecast bias from November to January, despite a reduction in HR-Histo bias during the same months, illustrates the effect of the model drift. The development of the forecast bias is relatively fast and it stabilizes to values close to the HR-Histo bias by the fourth month of the forecast.

Fig 3 compares the HR-Hind with respect to its low resolution counterpart LR-Hind, showing that increasing resolution leads to minor only improvements. Generally, higher resolution has a weak impact on the horizontal extent and the magnitude of the ETAWB, resulting in slightly weaker bias only during January and February, and in an area that corresponds to less than $8 \%$ of the total Tropical Atlantic area (between $30^{\circ} \mathrm{N}-30^{\circ} \mathrm{S}$ ), which is mostly located outside $\mathrm{CAB}$. This result suggests that an increase of the horizontal resolution in EC-Earth has a limited only impact in hindering the development of the ETAWB. Note: the vertical resolution used by the atmosphere component is the same in LR-Hind and HR-Hind, therefore we cannot assess the sensitivity of the ETAWB to this aspect.

The above results are summarized in Fig 4. Over CAB, the forecast bias in summer has already reached the same magnitude as the bias of HR-Histo by August (Fig 4). The rapid development of the forecast bias hints at mechanisms with short timescales, such as atmospheric or upper ocean mixing processes. In winter, over CAB, the ETAWB is already fully developed after four months of forecast and LR-Hind even overshoots afterwards. In the ocean-only experiment, LR-Ocean, the ETAWB is present in summer but is significantly smaller than in coupled experiments (magenta line in Fig 4a). This suggests that (at least) part of the ETAWB originates from unrealistically resolved features in the ocean component of EC-Earth, or deficiencies related to the surface forcing used in LR-Ocean. Winter forecasts with LR-Ocean do not exhibit the ETAWB, but even exhibit a slightly cold bias in January and February (Fig 4b). This suggests the possible "implication" of the atmosphere component or/and mechanisms inherent to the ocean-atmosphere coupling in the development of the ETAWB in coupled simulations.

\subsection{Mechanisms}

The spatial pattern and magnitude of the ETAWB are very similar between LR-Hind and HR-Hind (Fig 2 and 3). This suggests that the mechanisms that are responsible for the formation of the ETAWB are not sensitive to the horizontal resolution of the model, at least within the range of resolutions typically used in the context of climate integrations (resolutions of one quarter of a degree and below).

In the following, we investigate the different mechanisms that might be at play in the 
development and "sustainment" of the ETAWB. We focus on the LR-Hind experiment.

\subsubsection{Heat budget of the mixed layer}

The SST and the mean temperature of the ocean mixed layer (OML) are closely coupled and are commonly assumed proportional (e.g. Manabe and Stouffer, 1996; Deser et al., 2003).

The temperature trend in the OML is determined by the surface fluxes, the advection and diffusion of heat, and the entrainment at the base of the OML (e.g. Jouanno et al., 2011; Giordani et al., 2013; Planton, 2015). As such, the conservation of heat in the OML writes

$$
\begin{array}{r}
\frac{\partial T}{\partial t}=\underbrace{\frac{1}{\rho_{0} c_{p} h}\left[F_{\text {sol }}(I(0)-I(-h))\right]}_{\text {solar penetration }}+\underbrace{\frac{1}{\rho_{0} c_{p} h} F_{n s o l}}_{\text {non-solar surface flux input }} \\
\underbrace{-u \nabla T}_{\text {zonal advection }}-\underbrace{w \nabla T}_{\text {meridional advection } \quad \underbrace{v \nabla T}_{\text {vertical advection }}-\underbrace{\frac{1}{h} k_{z} \frac{\partial T}{\partial z}}_{\text {vertical diffusion }}+}+\underbrace{A_{H} \nabla^{2} T}_{\text {lateral diffusion }}-\frac{1}{h}[T-T(-h)] w_{e} \\
\text { entrainment }
\end{array}
$$

where $w_{e}=\partial h / \partial t+u \nabla h+w(-h)$ is the entrainment velocity, $T$ is the mean temperature in the OML, $\rho_{0}$ is a reference density, $c_{p}$ is the heat capacity of seawater, and $h$ is the OML depth (computed with a potential density criterion of $0.01 \mathrm{~kg} / \mathrm{m}^{3}$ with respect to the surface density). $F_{\text {sol }}$ is the net solar radiation at the surface, $I(z)$ is the absorption depth. $F_{n s o l}$ is the non-solar component of the surface heat flux (sum of the net longwave, sensible and latent heat fluxes). $k_{z}, A_{H}$ are the vertical and horizontal diffusion coefficients, respectively. The terms in Eq 1 are computed and time-averaged online during the simulation and are provided as 2D output diagnostics by NEMO. Note: the entrainment and the solar penetration terms are not computed explicitly. Instead, they are deduced from the residual of the heat budget and are saved together as a single diagnostic. To differentiate their respective contributions, we estimate the entrainment term offline as $(\partial T / \partial t)_{\text {entr }}=-\frac{1}{h}[T-T(-h)] \frac{d h}{d t}(\mathrm{Eq} 1)$, based on daily mean data of temperature and OML depth. The entrainment term "traduces/represents" the change of the mean temperature in the OML due to the variation of its depth $(\partial h / \partial t)$ and the vertical advection of water at the base of the OML (vertical velocity $w(-h)$ ). The shoaling and deepening of the OML (sign of $\partial h / \partial t$ ) have a warming and cooling impact, respectively. Similarly, positive (upwelling) and negative (downwelling) vertical velocities tend to cool and warm the OML, respectively (e.g. Giordani et al., 2013).

Even though the lack of process-based heat budget diagnostics from observational datasets or ocean reanalysis datasets prevents a direct comparison, we examine these diagnostics in conjunction with additional model output and infer hypothesis that apply in each case.

\subsubsection{CAB}

$\mathrm{CAB}$ is located slightly south of the region commonly associated with the EEACT (At13, $20^{\circ} \mathrm{W}-0,3^{\circ} \mathrm{S}-3^{\circ} \mathrm{N}$ ), and has similar seasonal variability to EEACT both in terms of OML 
temperature and depth (Peterson and Stramma, 1991). The development of the cold tongue occurs in late spring and early summer. It is associated with a seasonal increase of the Southern hemisphere trade winds and the northward migration of the ITCZ (Hastenrath and Lamb, 1978; Waliser and Gautier, 1993). The occurrence of the cold tongue is associated with a deepening and a cooling of the OML, and a drop in SST by roughly $5^{\circ} \mathrm{C}$ (Weingartner and Weisberg, 1991). The EEACT vanishes in wintertime as the OML shoals and the temperature of the OML returns to its warm state. Over CAB, the ETAWB in the model is associated with a lack of decrease in OML temperature during the development of the EEACT. The ETAWB is also associated to an unrealistic warming of the OML during the period under which the EEACT is "absent".

The net heat flux at the surface, $Q_{n e t}$, is the major contributor to the heat budget of the OML. Qnet consists of a solar contribution $Q_{S}$ (positive), which warms the surface layer of the OML, and a non-solar contribution $Q_{n s}$ (negative, sum of net longwave, sensible and latent heat fluxes), which cools the OML at the air-sea interface. In summer, Qnet is negative, the OML loses heat to the atmosphere as $\left|Q_{n s}\right|>Q_{S}$. In winter it is the opposite scenario, the OML gains heat because $\left|Q_{n s}\right|<Q_{S}$ (Fig 5a,b).

The OML depth has a net increase of about $4 \mathrm{~m}$ from May to the end of August, and a net decrease by about $0.5 \mathrm{~m}$ from November to the end of February. Entrainment has a cooling impact in the summer OML temperature (due to the deepening of the OML, $\partial d / \partial t>0$ and the associated entrainment of colder waters through the base of the OML) and a weak warming impact in the winter (due to the OML shoaling, $\partial d / \partial t<0$ ). During the OML shoaling, the warming might not be directly caused by detrainment of water masses (mass flux out of the OML), which have temperatures close to the OML mean temperature, but by the solar absorption (which is the dominant term in the OML heat budget), and which will warm a smaller volume of water. The total temperature change in the duration of the four months forecast caused by entrainment is very weak, with a magnitude of $-0.23^{\circ} \mathrm{C}$ in the summer and $0.05^{\circ} \mathrm{C}$ in the winter (brown lines in Fig 5a,b). These results are in line with previous studies that have found entrainment to be a weak contributor to the heat budget of the OML in the Equatorial Atlantic (Jouanno et al., 2011; Giordani et al., 2013; Planton, 2015).

The dynamic processes have a much weaker impact on the OML temperature than that of the heat fluxes. Meridional and zonal advection warm the OML by $0.04{ }^{\circ} \mathrm{C}$ from May to August and by $1.3^{\circ}$ from November to February (Fig 5a,b). Vertical mixing (green line in Fig 5a,b) results in a $-1^{\circ} \mathrm{C}$ temperature change in summer and $-2^{\circ} \mathrm{C}$ in winter. Vertical advection, associated with the cooling from the upwelling of colder water masses in this region, has a weak cooling impact, resulting in a $-0.2^{\circ} \mathrm{C}$ temperature change in summer and $-0.45^{\circ} \mathrm{C}$ in winter. The upwelling is localized north of the $\mathrm{CAB}$ box where the (cooling) vertical advection term is much stronger than in $\mathrm{CAB}$ with magnitude of 5 to 10 times stronger (not shown).

\subsubsection{Vertical advection}

Vertical velocities at the base of the OML are positive (Fig 6), consistent with the upwelling and the negative trends associated to vertical advection (green line in Fig 5a,b). The vertical velocities in LR-Hind have magnitude close to the ocean reanalysis, and even stronger than in SODA, except for November. The upwelling velocities are driven by the 
windstress curl. LR-Hind and QuikSCAT windstress curl fields are similar in both magnitude and spatial patterns, with the model slightly overestimating the magnitude close to the coast, which corresponds to an enhanced upwelling in the model (Fig 7). Additional sensitivity experiments, performed with the same model but with Atlantic windstress replaced by ERAi winds, show no significant impact on the ETAWB (Anna-Lena Deppenmeier, Wageningen University, personal communication). ETAWB in EC-Earth is therefore not related to underestimated windstress forcing at the ocean surface and insufficient ocean upwelling.

\subsubsection{Horizontal advection}

Examining the possibility of erroneous advection contributing to the ETAWB through misplaced Angola and Benguela currents, we compare the surface currents and subsurface meridional velocities $v$ of EC-Earth to ORAS4 (Figs 8,9). The southward AC and northward BC in ORAS4 converge at 16-18 ${ }^{\circ} \mathrm{S}$ (Figs 8c,d). In LR-Hind, in summer, there is a very weak southward flow; in winter there is a southward flow but with limited spatial extent and displaced to the north. The northward flow in LR-Hind is similar to ORAS4 with comparable magnitude, and even slightly stronger at $20-25^{\circ} \mathrm{S}$ (Fig 8e,f).

The subsurface front in ORAS4 seasonally varies, with a stronger BC in summer placing the front at $18^{\circ} \mathrm{S}$, and stronger southward extend of the $\mathrm{AC}$ in winter which moves the front southward at $25^{\circ} \mathrm{S}$ (Fig 9e,f). The northward cooling current in LR-Hind is stronger than in ORAS4 (favoring a cooling bias, Fig 9a,b). The southward subsurface current, however, is stronger in LR-Hind than in ORAS4 (favoring a warming bias). The structure of the southward subsurface current in LR-Hind is very similar to LR-Ocean (which has a very weak SST bias in winter and no bias in summer), therefore, not contributing to the warm SST bias, by either offsetting the cooling bias of the stronger northward current, or by simply not advecting enough heat to the region.

The location of the ABF and the structure of the surface and subsurface currents in LRHind and LR-Ocean suggest that horizontal advection of heat into CAB either by an anomalously strong AC or an anomalously weak BC, is not contributing to the ETAWB.

\subsubsection{Surface fluxes and solar penetration}

Strong positive biases (causing warming) in solar fluxes, that even reach $60 \mathrm{~W} / \mathrm{m}^{2}$ in some months, develop close to the east boundary of the Atlantic basin, over the CAB region (red line in Fig 11). The cause of solar flux biases is related to the anomalously low cloud cover (Fig 10, top row). The biases in the clouds and in the solar fluxes are present from the first day of the forecasts in LR-Hind (Fig S1), and they are also present in LR-Atm (Fig 10 , bottom row), suggesting that they are an inherent bias of the atmospheric model.

The biases in the other three components, i.e. the longwave, sensible and latent heat fluxes (brown, blue and green lines in Fig 11), are negative, tending to oppose the warming created by the solar fluxes. The bias in the net surface heat fluxes (black line in Fig 11) over $\mathrm{CAB}$ is negative in all months except for November and December. We note here that when changing the reference observation dataset to OAFlux (Jin and Weller, 2008), the biases in next heat fluxes remain negative in all months, including November and December (Fig S3), reflecting the observational uncertainty in this region. The cooling caused from the latent and longwave fluxes is likely a response to the SST warming, illustrated 
by the antisymmetrical latent heat fluxes to the SST biases in Fig 11. The overcompensation of latent heat fluxes to the excessive solar heat fluxes is a common feature among CMIP5 models (Xu et al., 2014a). Other sources of latent heat flux biases would be linked to wind biases. However, given that the sensitivity experiments with Atlantic windstress replaced by ERAi winds (mentioned in Section 3.2.3) show no significant impact on the ETAWB, it does not seem likely that sources other than the response to the warm SST bias are important in generating the negative biases in the latent heat flux.

The ETAWB in November and December can be directly linked to the excessive net surface heat fluxes, caused in turn by the excessive solar forcing in those months. During the summer months, and January and February, there is an apparent inconsistency between the ETABW and the negative bias in the net surface heat fluxes. Given that we already have ruled out any other potential contributor to ETAWB, despite the reduced input of energy at the surface, a warming in the OML can still occur through subsurface anomalies in solar absorption. A solar flux at the OML base that is underestimated by a value equal or larger than the magnitude of the net surface heat flux bias will create a positive anomaly in the solar absorption in the OML and will offset the non-solar cooling anomaly at the surface. Such a subsurface anomaly in solar absorption can be directly linked to assumptions of the solar scheme, as discussed in more detail below. A positive anomaly in solar absorption in the OML will trigger an OML warming that will lead to a more stable water column, i.e. a water column with steeper vertical density and vertical temperature gradient, and a shallower OML depth. The OML depth shoaling will lead to less solar absorption (the nominator $\left[F_{\text {sol }}(I(0)-I(-h))\right]$ in first term of Eq. 1) which will cool the OML. The OML shoaling will also lead to OML warming through the smaller $h$ (appearing in the denominator of the same term, $1 / \rho_{0} c_{p} h$, in Eq. 1). The second effect is more dominant than the first, due to the exponential profile of solar absorption, thus the result in this case will be a net OML warming.

Consistent with this view, the OML depth in HR-Hind is thinner than in GLORYS (Fig 12). The model is also more stabilized in terms of its vertical gradient in potential density compared to GLORYS (Fig 13). A note here: we compare the HR-Hind OML depth to GLORYS because they have identical vertical discretizations ( $75 \mathrm{z}$-levels). It is not straightforward to compare LR-Hind to ORAS4: LR has 46 z-levels and ORAS4 has 42 z-levels, because the differences in vertical discretization between LR-Hind and ORAS4 are similar to their OML depth differences.

We assess the impact of the solar penetration on the OML temperature and depth, and thus on the ETAWB, by modifying the solar penetration scheme in NEMO. The parameterization for solar penetration in NEMO follows the 2-waveband method of Lengaigne et al. (2007). The solar energy $Q_{s r}$ at large wavelengths (larger than $700 \mathrm{~nm}$ ) is strongly absorbed at the top few centimeters of the sea surface (set to $58 \%$ of the total surface irradiance), while the energy at wavelengths between 400 and $700 \mathrm{~nm}$ penetrates the ocean and contributes to subsurface heating (assumed $42 \%$ of the total surface irradiance). This is a crude approximation of a more complicated light absorption process, which is computationally expensive to implement in models (Morel, 1988). The profile of the solar radiation flux within the ocean $I_{p e n}(z)$ for a given surface solar radiation input $Q_{s r}$ is then defined by these two wavebands, their penetration depths $h_{1}, h_{2}$, and their fractional ratio 
$R$. The penetrative solar irradiance is assumed to follow an exponential profile

$$
I_{\text {pen }}(z)=Q_{s r}\left(R e^{z / h 1}+(1-R) e^{z / h 2}\right) .
$$

The default values in NEMO are $R=0.58, h 1=0.35 \mathrm{~m}$, and $h 2=23 \mathrm{~m}$. We perform a sensitivity experiment (LR-Hind-Sol, table 1) with depth $h 2$ increased to $50 \mathrm{~m}$, which leads to larger solar radiation flux through the bottom of the mixed layer, hence a weaker solar absorption in the OML. The solar absorption in the OML of LR-Hind-Sol reduces by a value comparable to the bias in the surface solar fluxes. For example, for a surface radiation value of $Q_{s r}=260 \mathrm{~W} / \mathrm{m}^{2}$ (equal to the LR-Hind solar fluxes in May), and an OML depth of $20 \mathrm{~m}$, the solar absorption reduces by about $28 \mathrm{~W} / \mathrm{m}^{2}$ stronger than in LRHind (Fig 14). This value is comparable to the actual bias in the surface solar fluxes in May (Fig 11a).

Solar penetration is an important term in the OML budget (Hieronymus and Nycander, 2013), and increasing the solar penetration depth is expected to lead to deeper and colder OML, as well as a weaker SST bias. This result is not guaranteed; the latent and longwave heat fluxes of the model, which tend to oppose and overcompensate the solar warming, are expected to decrease in magnitude if the SST bias in LR-Hind-Sol is reduced, thus leading to less cooling (hence contributing to a warm bias). Indeed, the magnitudes of latent and longwave fluxes decrease in LR-Hind-Sol, as discussed below.

Results with the LR-Hind-Sol show that the OML becomes deeper and colder (Fig 5c,d) and that the ETAWB is reduced by a third in the summer, while it is eradicated in the winter (Fig 4a,b). Those changes are directly linked to the weaker solar absorption in the OML but also to the increase in the OML depth (Fig 5c,d). The changes in the non-solar surface forcing are in the opposite direction but with weaker magnitude (Fig 5c,d).

The stronger winter response of the OML temperature to the modified solar penetration depth, as compared to the summer response, can be linked to the winter OML depth. The winter OML depth is about half than the summer and with only a modest increase in LR-Hind-Sol. In the thinner winter OML there is a stronger solar flux at the OML base, leaving weaker solar absorption within the OML. In summer, most of the solar energy is already absorbed in the OML and the change in solar penetration has a weaker impact on its temperature. Furthemore, assuming that solar penetration has no spatial or temporal variation is a crude approximation, particularly in the East Tropical Atlantic where the biological activity displays a pronounced seasonal cycle with concentration of biological elements changing as much as fivefold within a year (Monger et al., 1997; Christian and Murtugudde, 2003). The impact of more realistic penetration of the solar flux on ETAWB should be fully assessed with implementing and testing schemes that take into account the spatial and temporal variability of biological production.

ETAWB is, therefore, likely linked to excessive solar penetration in the OML and subsequent OML depth changes, a result of excessive surface solar fluxes and a crude solar penetration scheme that does not take into account the spatial and the temporal variability of light attenuation. The presence of a weak ETAWB only in summer in LR-Ocean suggests errors of oceanic origin or deficiencies in the ocean forcing dataset (DFS4.3). A weak solar flux bias of DFS4.3 is found to occur at the east boundary (reaching $20 \mathrm{~W} / \mathrm{m}^{2}$ ), where the warm bias in OML develops (Fig 15). There are no significant changes between the DFS4.3 winds and QuickSCAT over CAB (Fig S2). The seasonality of LROcean ETAWB can also be related to the seasonal cycle of the biological production and 
associated solar penetration, as hypothesized above.

With performing the LR-Hind-Sol sensitivity experiment we do not indend to suggest a precise value for the solar penetration depth $h 2$. Determining the details of an improved solar penetration scheme is beyond the scope of our study. The purpose of the LR-HindSol experiment is to highlight and assess the impact of modified solar absorption on the OML temperature and OML depth, and thus on the ETAWB, and point to a particular direction for future model developments.

Finally, while the results with the LR-Hind-Sol sensitivity experiment highlight the importance of solar penetration on the ETAWB, a caveat is that, due to the short forecast length, we cannot assess here the effects over longer time scales. Our current results, however, motivate future directions in exploring different solar schemes and their impacts on SST biases.

\subsubsection{Vertical mixing}

The turbulent vertical mixing in NEMO follows the turbulent kinetic energy (TKE) turbulent closure model (Gaspar et al., 1990; Madec, 2008). In addition to the TKE scheme, NEMO also includes a Langmuir cell parameterization (Axell, 2002) and a surface wave breaking parameterization (Mellor and Blumberg, 2004). The eddy diffusivities are a function of the TKE according to

$$
K=c_{k} l_{k} \sqrt{e} / P_{r t}
$$

where $e$ is the TKE, $c_{k}$ a constant, $l_{k}$ the dissipation length scale, and $P_{r t}$ the Prandtl number. We performed several sensitivity experiments with modified parameters of the TKE scheme in the coupled model. One only of those experiments resulted in a significant reduction of the ETAWB (LR-Hind-Dif). Four terms were modified: $c_{k}$ was increased from 0.1 to 0.2 . The value of $c_{k}$ in the TKE scheme is chosen so as to be related to the mixing efficiency $\gamma$, which quantifies the ratio of the available potential energy to kinetic energy dissipation (Gaspar et al., 1990; Lindborg and Brethouwer, 2008). The value of $\gamma$ is uncertain and there is a range of values proposed in the literature (e.g. Moum et al., 1989), implying a similar range of values for $c_{k}$. The value chosen in LR-Hind-Dif $\left(c_{k}=0.2\right)$ is within this range and not unrealistic. Second, the term rn_ebb, related to the surface boundary condition of TKE (Madec, 2008), was doubled to 67.83, which is the default value of NEMO. The coupled simulations use $r n \_e b b=33.92$, which was found from previous sensitivity experiments to have a warming impact on mid-latitudes SST in the summer hemisphere, thereby reducing the cold bias in those regions, but only a weak impact on the tropics. The third modification was an increase of the coefficient of the Langmuir cells scheme from 0.15 to 0.3 , which is within the range of values suggested by Axell (2002). Finally, the fourth modification, and likely the most significant, deals with the fraction of TKE that penetrates below the OML, which was increased from 0.05 to 0.1 .

The ETAWB of LR-Hind-Dif in summer is reduced by a third, while in winter it is eliminated completely (Fig 4a,b, blue line). These results suggest that NEMO has insufficient vertical mixing which partly contributes to the warm SST bias. Uniformly increasing the vertical mixing, however, has the caveat that the cold biases deteriorate. Increasing uniformly the vertical diffusivity is a crude approximation, and the spatial variability of 
diffusivity should be taken into account. A source of spatial variability in diffusivity arises from near inertial mixing as a response to high frequency wind forcing (D'Asaro, 1985; Garrett, 2001, e.g.). Taking inertial mixing into account could potentially lead to significant improvements in the OML heat budget and the SST biases. Spatially varying diffusivities can also occur from breaking of internal tides over rough topography and near continental slopes or shallow coastal boundaries (Toole et al., 1994; Polzin and Firing, 1997; Ledwell et al., 2000; Nash et al., 2004).

\section{Summary and discussion}

We investigated the mechanisms responsible for the development of the warm SST bias that forms over the eastern Tropical Atlantic in the EC-Earth climate model. The fullydeveloped bias has been identified using a 40 year long historical experiment at high horizontal resolution, HR-Histo (1960-2000). The development of the bias when the model is initialized from observations, which we refer to as the drift, has been analyzed by means of a series of 4 month long retrospective prediction experiments, initialized from an observed state in May and November (spanning 1993-2009). These retrospective predictions were performed at both standard and high horizontal resolution. Ocean- and atmosphereonly forced experiments were also performed to help identify the respective contributions of the ocean and atmosphere components of EC-Earth (LR-Ocean and LR-Atm). In order to examine different hypothesis about the origins of the bias, we performed sensitivity experiments with different solar penetration and vertical mixing schemes.

Our main conclusions are:

- EC-Earth 3.1 exhibits a warm SST bias in the eastern Tropical Atlantic, with a spatial pattern similar to that of other CMIP models, but with a weaker magnitude.

- Significantly increasing the horizontal resolution of both the atmospheric and ocean components only results in minor improvements in terms of horizontal extent and magnitude of the warm SST bias.

- The warm SST bias is found to be the result of an excessive solar absorption in the ocean mixed layer, which can be linked to the excessive solar insolation due to unrealistically low cloud cover, and the absence of spatial and temporal variability of the biological productivity in the ocean component, which can lead to underestimated penetration of solar energy below the mixed layer, and a shoaling and further warming of the ocean mixed layer.

- The warm SST bias is also partly a consequence of the underestimation of the vertical turbulent mixing by the ocean component; this limits the mixing of the surface layer with underlying colder water masses.

In EC-Earth, contrarily to what has been reported in other AOGCMs (e.g. Richter, 2015), the eastern Tropical Atlantic warm SST bias is not linked to an unrealistic representation of the surface wind stress. Moreover, the fact that the warm SST bias in typical CMIP5 AOGCMs was more pronounced, and partly linked to unrealistic wind stress, suggests that more recent versions of AOGCMs like EC-Earth, which develop a weaker bias, got 
rid of the unrealistic wind stress contribution. In these more recent AOGCMs, most of the other aspects discussed in this paper still seem to contribute to the warm bias, such as unrealistic surface heat fluxes, vertical physics, etc.

The impact of the vertical resolution in the atmosphere component on the warm bias has not been assessed in our study. This remains to be done, in particular with a focus on the impact of higher vertical resolution on the representation of clouds and solar flux at the surface. Furthermore, the effect of switching to ultra-high eddy-resolving horizontal resolution in the ocean component should also be assessed.

Based on our results, we suggest that in order to reduce the eastern Tropical Atlantic warm SST bias in EC-Earth, future work should first address the problematic aspects identified in the atmosphere and ocean components, separately. As such, the future development of the atmosphere component, IFS, should aim at improving the cloud representation in the vicinity of eastern boundaries, typically over coastal upwelling regions. In the ocean component, NEMO, more realistic and more sophisticated vertical physics is needed. The need of more realistic vertical mixing is currently addressed through the introduction of new turbulence closure schemes such as GLS $^{3}$ (Umlauf and Burchard, 2003) and that developed in the framework of the OSMOSIS ${ }^{4}$ consortium. More realistic penetration of the solar flux should be achieved by implementing schemes that take into account the spatial and temporal variability of biological production.

\section{Acknowledgements}

We would like to acknowledge the anonymous reviewer who provided constructive comments that led to a considerable improvement of the manuscript. We would also like to thank Aurore Voldoire and Anna-Lena Deppenmeier for the useful discussion, and Yann Planton for providing the code for implementing the tendency diagnostics in NEMO. This research has received funding from the EU Seventh Framework Programme FP7 (20072013) under grant agreements 308378 (SPECS), 603521 (PREFACE) and the Horizon 2020 EU program under grand agreements 641727 (PRIMAVERA). We acknowledge RES and ECMWF for awarding access to supercomputing facilities in the Barcelona Supercomputing Center in Spain and the ECMWF Supercomputing Center in the UK, through the HiResClim and SPESICCF projects, recpectively. We acknowledge the work of the developers of the s2dverification R-based package (http://cran.r-project. $\mathrm{org} /$ web/packages/s2dverification/index.html). The visualization of some of the figures was done with the NCAR Command Language (NCL, Version 6.3.0, 2016, Boulder, Colorado: UCAR/NCAR/CISL/TDD, http://dx . doi .org/10.5065/D6WD3XH5).

\footnotetext{
${ }^{3}$ Generic Length Scale

${ }^{4}$ Ocean Surface Mixing, Ocean Sub-mesoscale Interaction Study, https://www.bodc.ac.uk/ projects/data_management/uk/osmosis/
} 


\section{List of Tables}

1 Summary of the experiments used in this study. . . . . . . . . . . . . . . 19

\section{List of Figures}

1 Bias in $\mathrm{SST}$ (in ${ }^{\circ} \mathrm{C}$ ) for the HR-Histo experiment with respect to HadISST. The bias is calculated as the difference between HR-Histo and HadISST in their time mean over 40 years (1960-1999) for each month. The summer months (May-August) are shown in the top row and the winter months (November to February) in the bottom row. The boxes denote the CAB

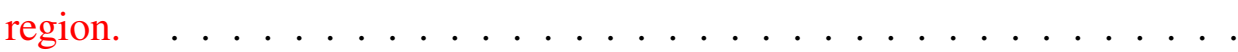

Forecast bias in SST (in ${ }^{\circ} \mathrm{C}$ ) for the experiment HR-Hind with respect to HadISST for the forecast initialized in May (top row) and November (bottom row). The bias is calculated as the difference between HR-Hind and HadISST in their average over 17 years (1993-2009) for each forecast month. The boxes denote the $\mathrm{CAB}$ region. . . . . . . . . . . .

3 Difference in SST between the LR-Hind and HR-Hind (LR-Hind minus HR-hind). Dotted (dashed) areas indicate regions where the LR-Hind experiment has significantly larger (smaller) bias (at a 90\% confidence level) than HR-Hind (HadISST is used as a reference observational dataset). Please note that the colour levels correspond to half the ones used in Figs

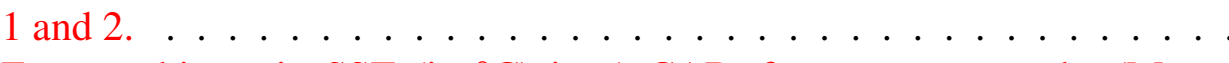
Forecast biases in $\mathrm{SST}\left(\right.$ in ${ }^{\circ} \mathrm{C}$ ) in a) $\mathrm{CAB}$, for summer months (MayAugust), b) CAB, for winter months (November-February). The bias of the HR-Histo with respect to HadISST, for the corresponding months, but for the period of 1960-1999, is also shown. . . . . . . . . . . . Daily mean temperature tendencies (in ${ }^{\circ} \mathrm{C} /$ month) of Eq 1 (colored lines) and daily mean mixed layer depth where this tendencies are calculated (defined with a density criterion of $0.01 \mathrm{~kg} / \mathrm{m}^{3}$ compared to the density at $10 \mathrm{~m}$ depth, dashed grey line corresponding to values in right $\mathrm{Y}$ axis) in CAB for LR-Hind (top row) and the difference in tendencies LR-HindSol minus LR-Hind (bottom row) for the period of May to August (panels a) and c)) and November to February (panels b) and d)). The total temperature tendency from ESA is also shown (grey line). Please note the irregular left $\mathrm{Y}$ axis in $\mathrm{a})$ and $\mathrm{b}) . \ldots \ldots \ldots$

6 Monthly mean vertical velocities as a function of depth (in $10^{-6} \mathrm{~m} / \mathrm{s}$ ), area averaged over the CAB region, for LR-Hind (top row), ORAS4 reanalysis (middle) and SODA reanalysis (bottom row), for summer months (MayAugust, left) and winter months (November-February, right). Positive (negative) vertical velocities are upward (downward) . . . . . . . . . 
7 Seasonal mean windstress curl (in m/s per $100 \mathrm{~km}$ ) for LR-Hind (top row) and QuickSCAT data (bottom row), averaged over the summer months (May-August, left) and winter months (November-February, right). Negative means counter-clockwise rotation, inducing upwelling and vice-versa.

Ocean surface currents (vectors, in $\mathrm{m} / \mathrm{s}$ ) where contours show the currents magnitudes (in $\mathrm{m} / \mathrm{s}$ ), for summer (May-August, left) and winter (November-February, right), for LR-Hind (top) and ORAS4 (middle) and LR-Hind minus ORAS4 (bottom). . . . . . . . . . . . . . . Meridional ocean velocities $v$ (in $\mathrm{m} / \mathrm{s}$, positive values are northward), averaged from the coast to 2 degrees offshore for LR-Hind (top), LR-Ocean (middle) and ORAS4 (bottom) averaged over the summer months (MayAugust, left) and winter months (November-February, right). Color contour intervals are $0.01 \mathrm{~m} / \mathrm{s}$, line contour intervals are $0.02 \mathrm{~m} / \mathrm{s}$. . . . . . .

10 The colored contours denote the forecast biases in downward solar fluxes for the LR-Hind experiment with respect to TropFlux, for May and November. The hatched pattern denotes areas where the model has at least 5\% less total cloud fraction than observations, whereas the dashed pattern denotes areas where the model has at least 5\% more total cloud fraction then observations (cloud fraction is daytime only). The reference dataset for total cloud cover observations is ISCCP. . . . . . . . . . . . Forecast biases in the four components of the meridionally averaged (between $18^{\circ} \mathrm{S}-5^{\circ} \mathrm{S}$ ) surface heat fluxes (positive is downwards, units are $\mathrm{W} / \mathrm{m}^{2}$ ) for the LR-Hind experiment with respect to TropFlux. Sensible heat fluxes are shown in green, latent in blue, longwave in brown, shortwave in red, and net heat fluxes in black, for the the summer months (May-August) in the top row and winter months (November-February) in the bottom row. The grey line is the SST bias (with respect to HadISST), and its values are shown in the right $\mathrm{Y}$ axis. . . . . . . . . . .

12 Forecast bias in OML depth (in $\mathrm{m}$ ) for the HR-Hind experiment with respect to GLORYS. The bias is calculated as the difference between HRHind and GLORYS in their average over 17 years (1993-2009) for each forecast month. The summer months (May-August) are shown in the top row and the winter months (November to February) in the bottom row. Dashed values denote statistically siginificant changes based on a Student's t-test (at a $95 \%$ confidence level). . . . . . . . . . . . . . . .

13 Forecast bias in potential density gradient of $\sigma_{0}$, defined as the difference
between the $\sigma_{0}$ at $100 \mathrm{~m}$ minus $\sigma_{0}$ at sea surface $\left(\mathrm{in} \mathrm{kg} / \mathrm{m}^{3}\right.$ ) for the LR-
Hind experiment with respect to GLORYS. The bias is calculated as the
difference between HR-Hind and GLORYS in their average over 17 years
(1993-2009) for each forecast month. The summer months (May-August)
are shown in the top row and the winter months (November to February)
in the bottom row. Positive (negative) values denote that LR-Hind is more
(less) stable than GLORYS. . . . . . . . . . . . . . . . . . . .

13 Forecast bias in potential density gradient of $\sigma_{0}$, defined as the difference
between the $\sigma_{0}$ at $100 \mathrm{~m}$ minus $\sigma_{0}$ at sea surface $\left(\mathrm{in} \mathrm{kg} / \mathrm{m}^{3}\right.$ ) for the LR-
Hind experiment with respect to GLORYS. The bias is calculated as the
difference between HR-Hind and GLORYS in their average over 17 years
(1993-2009) for each forecast month. The summer months (May-August)
are shown in the top row and the winter months (November to February)
in the bottom row. Positive (negative) values denote that LR-Hind is more
(less) stable than GLORYS. . . . . . . . . . . . . . . . . . . . .

13 Forecast bias in potential density gradient of $\sigma_{0}$, defined as the difference
between the $\sigma_{0}$ at $100 \mathrm{~m}$ minus $\sigma_{0}$ at sea surface $\left(\mathrm{in} \mathrm{kg} / \mathrm{m}^{3}\right.$ ) for the LR-
Hind experiment with respect to GLORYS. The bias is calculated as the
difference between HR-Hind and GLORYS in their average over 17 years
(1993-2009) for each forecast month. The summer months (May-August)
are shown in the top row and the winter months (November to February)
in the bottom row. Positive (negative) values denote that LR-Hind is more
(less) stable than GLORYS. . . . . . . . . . . . . . . . . . . . .

13 Forecast bias in potential density gradient of $\sigma_{0}$, defined as the difference
between the $\sigma_{0}$ at $100 \mathrm{~m}$ minus $\sigma_{0}$ at sea surface $\left(\mathrm{in} \mathrm{kg} / \mathrm{m}^{3}\right.$ ) for the LR-
Hind experiment with respect to GLORYS. The bias is calculated as the
difference between HR-Hind and GLORYS in their average over 17 years
(1993-2009) for each forecast month. The summer months (May-August)
are shown in the top row and the winter months (November to February)
in the bottom row. Positive (negative) values denote that LR-Hind is more
(less) stable than GLORYS. . . . . . . . . . . . . . . . . . . . .

13 Forecast bias in potential density gradient of $\sigma_{0}$, defined as the difference
between the $\sigma_{0}$ at $100 \mathrm{~m}$ minus $\sigma_{0}$ at sea surface $\left(\mathrm{in} \mathrm{kg} / \mathrm{m}^{3}\right.$ ) for the LR-
Hind experiment with respect to GLORYS. The bias is calculated as the
difference between HR-Hind and GLORYS in their average over 17 years
(1993-2009) for each forecast month. The summer months (May-August)
are shown in the top row and the winter months (November to February)
in the bottom row. Positive (negative) values denote that LR-Hind is more
(less) stable than GLORYS. . . . . . . . . . . . . . . . . . . . .

13 Forecast bias in potential density gradient of $\sigma_{0}$, defined as the difference
between the $\sigma_{0}$ at $100 \mathrm{~m}$ minus $\sigma_{0}$ at sea surface $\left(\mathrm{in} \mathrm{kg} / \mathrm{m}^{3}\right.$ ) for the LR-
Hind experiment with respect to GLORYS. The bias is calculated as the
difference between HR-Hind and GLORYS in their average over 17 years
(1993-2009) for each forecast month. The summer months (May-August)
are shown in the top row and the winter months (November to February)
in the bottom row. Positive (negative) values denote that LR-Hind is more
(less) stable than GLORYS. . . . . . . . . . . . . . . . . . . . .

13 Forecast bias in potential density gradient of $\sigma_{0}$, defined as the difference
between the $\sigma_{0}$ at $100 \mathrm{~m}$ minus $\sigma_{0}$ at sea surface $\left(\mathrm{in} \mathrm{kg} / \mathrm{m}^{3}\right.$ ) for the LR-
Hind experiment with respect to GLORYS. The bias is calculated as the
difference between HR-Hind and GLORYS in their average over 17 years
(1993-2009) for each forecast month. The summer months (May-August)
are shown in the top row and the winter months (November to February)
in the bottom row. Positive (negative) values denote that LR-Hind is more
(less) stable than GLORYS. . . . . . . . . . . . . . . . . . . . .

13 Forecast bias in potential density gradient of $\sigma_{0}$, defined as the difference
between the $\sigma_{0}$ at $100 \mathrm{~m}$ minus $\sigma_{0}$ at sea surface $\left(\right.$ in $\mathrm{kg} / \mathrm{m}^{3}$ ) for the LR-
Hind experiment with respect to GLORYS. The bias is calculated as the
difference between HR-Hind and GLORYS in their average over 17 years
(1993-2009) for each forecast month. The summer months (May-August)
are shown in the top row and the winter months (November to February)
in the bottom row. Positive (negative) values denote that LR-Hind is more
(less) stable than GLORYS. . . . . . . . . . . . . . . . . . .

14 Vertical profiles of solar flux with depth (in $\mathrm{W} / \mathrm{m}^{2}$ ) for LR-Hind and LRHind-Sol, for a surface solar radiation of $Q_{s r}=260 \mathrm{~W} / \mathrm{m}^{2}$. . . . . . . . . 
15 Forecast biases for the summer months (May-August), meridionally averaged between $18^{\circ} \mathrm{S}-5^{\circ} \mathrm{S}$, for the LR-Ocean experiment for (top row) the surface heat fluxes, with respect to TropFlux (positive is downwards, units are $\mathrm{W} / \mathrm{m}^{2}$ ). The LR-Ocean is forced by DFS4.3 (Table 1), therefore the biases in solar fluxes are DFS4.3 biases. The grey line is the SST bias (with respect to HadISST), and its values are shown in the right $\mathrm{Y}$ axis, in ${ }^{\circ} \mathrm{C}$. Bottom row: the potential ocean temperature in the top $300 \mathrm{~m}$, with respect to GLORYS, in ${ }^{\circ} \mathrm{C}$. Contour interval is $0.2^{\circ} \mathrm{C}$. . . . . . . . . .

S1 Forecast biases in the four components of the area-averaged surface heat fluxes over the CAB region (positive is downwards, units are $\mathrm{W} / \mathrm{m}^{2}$ ) for the LR-Hind experiment with respect to TropFlux. Sensible heat fluxes are shown in green, latent in blue, longwave in brown, shortwave in red, and net heat fluxes in black, for the the summer months (May-August) in the top row and winter months (November-February) in the bottom row. The grey line is the SST bias (with respect to ERAi), and its values are shown in the right $\mathrm{Y}$ axis, in ${ }^{\circ} \mathrm{C}$. The biases are calculated as the difference between LR-Hind and the reference dataset (TropFlux or ERAi) in their time mean data over 17 years (1993-2009) for each day in May (left) and

S2 Climatological meridional surface wind speed vas $($ in $\mathrm{m} / \mathrm{s}$, time averages between 1999-2009), and zonally averaged between $25^{\circ} \mathrm{S}-5^{\circ} \mathrm{S}$, for DFS4.3 and QuikSCAT.

S3 Forecast biases in the four components of the meridionally averaged (between $18^{\circ} \mathrm{S}-5^{\circ} \mathrm{S}$ ) surface heat fluxes (positive is downwards, units are $\mathrm{W} / \mathrm{m}^{2}$ ) for the LR-Hind experiment with respect to OAFlux (as in Fig 15). 


\begin{tabular}{|c|c|c|c|c|c|c|c|}
\hline Exp & HR-Histo & HR-Hind & LR-Hind & LR-Hind-Sol & LR-Hind-Dif & LR-Ocean & LR-Atm \\
\hline Resolution & $\begin{array}{l}\text { T511L91- } \\
\text { ORCA025L75 }\end{array}$ & $\begin{array}{l}\text { T511L91- } \\
\text { ORCA025L75 }\end{array}$ & $\begin{array}{l}\text { T255L91- } \\
\text { ORCA1L46 }\end{array}$ & $\begin{array}{l}\text { T255L91- } \\
\text { ORCA1L46 }\end{array}$ & $\begin{array}{l}\text { T255L91- } \\
\text { ORCA1L46 }\end{array}$ & ORCA1L46 & T255L91 \\
\hline Ensemble members & 1 & 10 & 10 & 1 & 1 & 5 & 5 \\
\hline Start date & 1st January 1960 & $\begin{array}{l}\text { 1st May \& 1st } \\
\text { November }\end{array}$ & $\begin{array}{l}\text { 1st May \& 1st } \\
\text { November }\end{array}$ & $\begin{array}{l}\text { 1st May \& 1st } \\
\text { November }\end{array}$ & $\begin{array}{l}\text { 1st May \& 1st } \\
\text { November }\end{array}$ & $\begin{array}{l}\text { 1st May \& 1st } \\
\text { November }\end{array}$ & $\begin{array}{l}\text { 1st May \& 1st } \\
\text { November }\end{array}$ \\
\hline Duration & 40 years & 4 months & 4 months & 4 months & 4 months & 4 months & 4 months \\
\hline Period & $1960-2000$ & 1993-2009 & 1993-2009 & 1993-2009 & 1993-2009 & 1993-2006 & 1993-2009 \\
\hline Atm initialization & Spin-up & ERAi & ERAi & ERAi & ERAi & - & ERAi \\
\hline Ocean initialization & Spin-up & GLORYS2V1 & GLORYS2V1 & GLORYS2V1 & GLORYS2V1 & GLORYS2V1 & - \\
\hline Ice initialization & Spin-up & GLORYS2V1 & GLORYS2V1 & GLORYS2V1 & GLORYS2V1 & GLORYS2V1 & - \\
\hline Ocean forcing & - & - & - & - & - & DFS4.3 & - \\
\hline Atmosphere forcing & - & - & - & - & - & - & ERAi \\
\hline Context & Historical run & Seasonal hindcast & Seasonal hindcast & $\begin{array}{l}\text { Seasonal hindcast, } \\
\text { solar penetration } \\
23 \mathrm{~m} \rightarrow 50 \mathrm{~m}\end{array}$ & $\begin{array}{l}\text { Seasonal hindcast, } \\
\text { enhanced vertical } \\
\text { diffusion }\end{array}$ & $\begin{array}{l}\text { Seasonal hindcast, } \\
\text { standalone ocean }\end{array}$ & $\begin{array}{l}\text { Seasonal hind- } \\
\text { cast, standalone } \\
\text { atmosphere }\end{array}$ \\
\hline
\end{tabular}

Table 1: Summary of the experiments used in this study. 

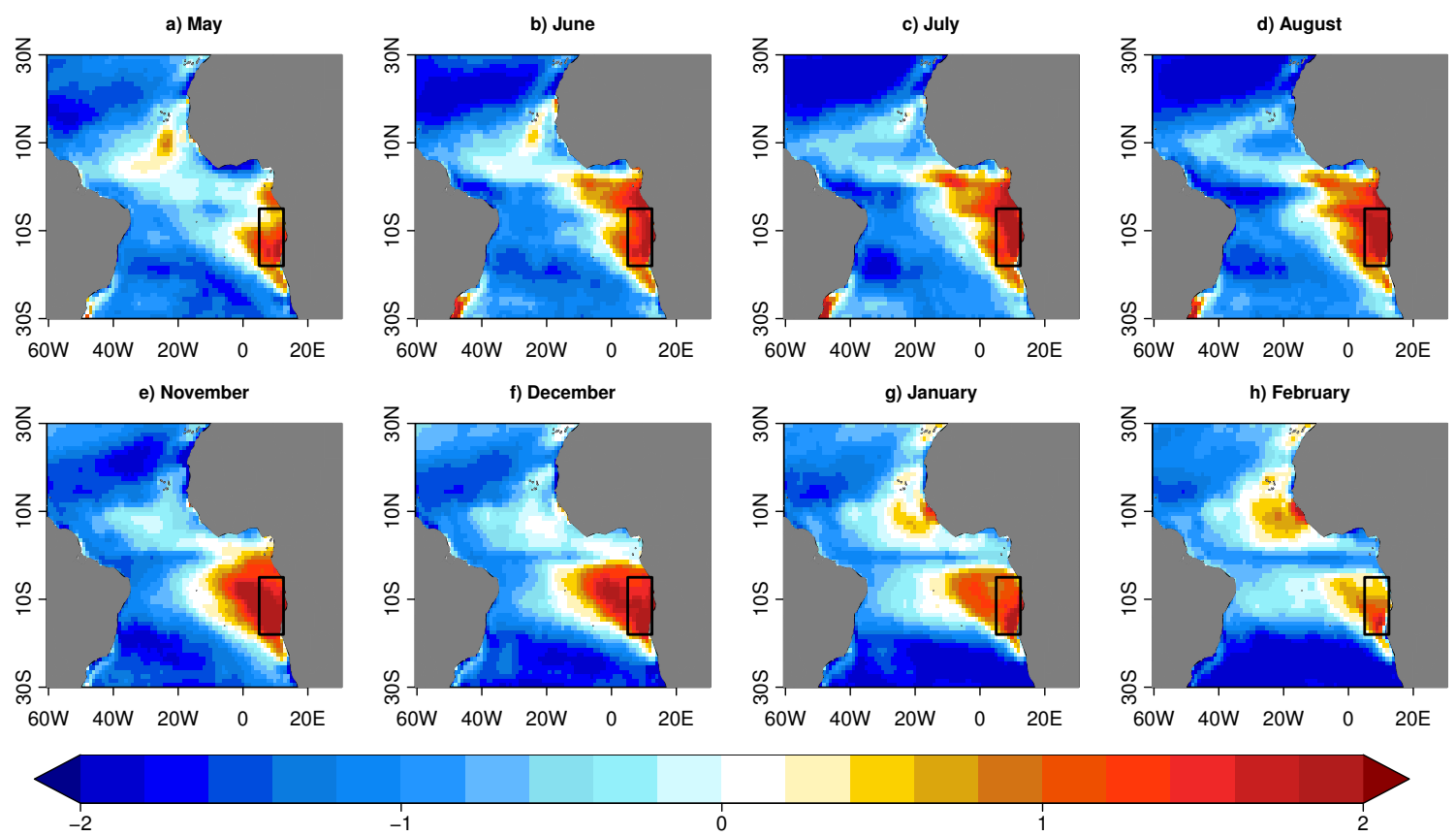

Figure 1: Bias in SST (in ${ }^{\circ} \mathrm{C}$ ) for the HR-Histo experiment with respect to HadISST. The bias is calculated as the difference between HR-Histo and HadISST in their time mean over 40 years (1960-1999) for each month. The summer months (May-August) are shown in the top row and the winter months (November to February) in the bottom row. The boxes denote the CAB region.
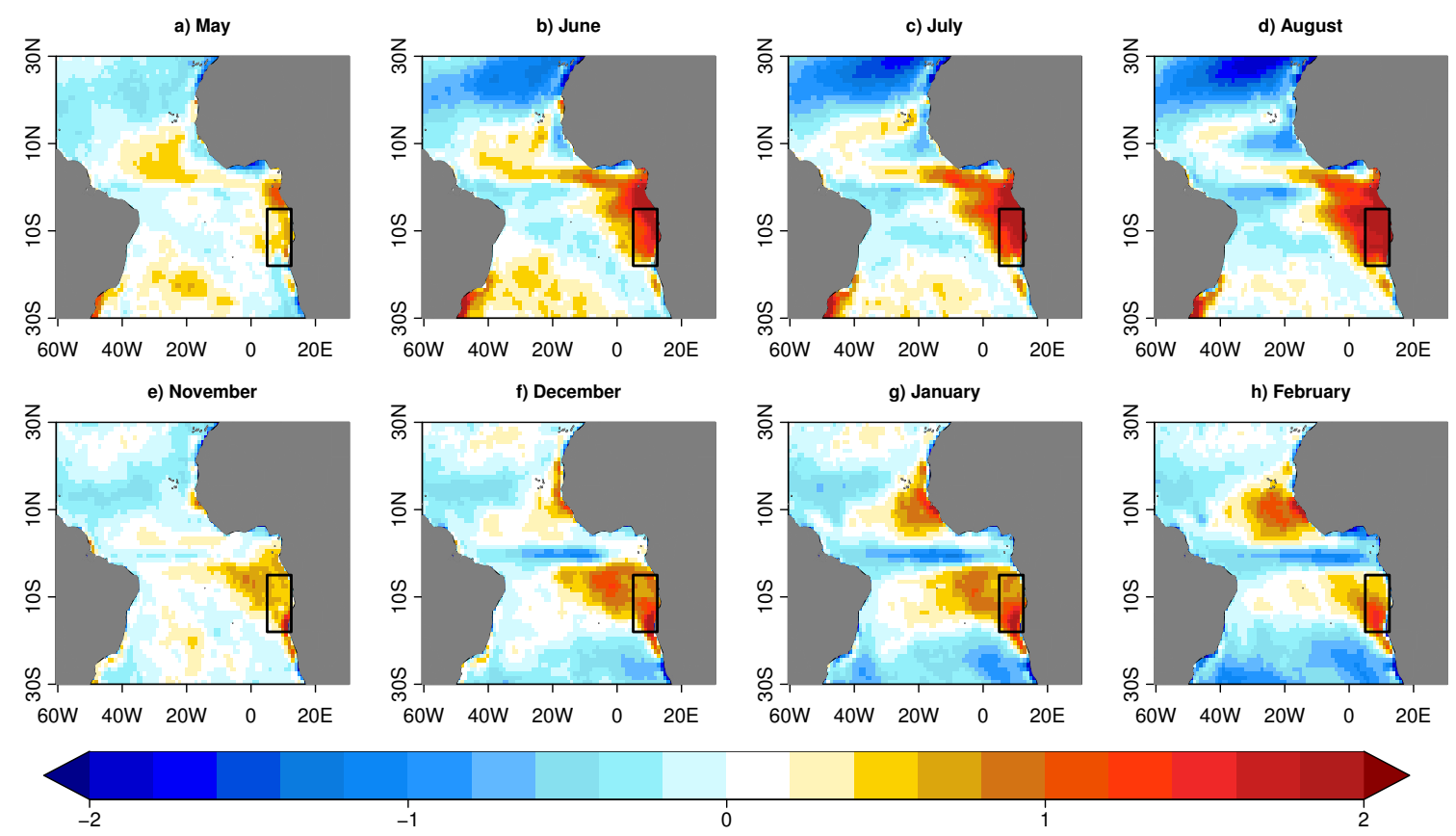

Figure 2: $\quad$ Forecast bias in SST (in ${ }^{\circ} \mathrm{C}$ ) for the experiment HR-Hind with respect to HadISST for the forecast initialized in May (top row) and November (bottom row). The bias is calculated as the difference between HR-Hind and HadISST in their average over 17 years (1993-2009) for each forecast month. The boxes denote the $\mathrm{CAB}$ region. 

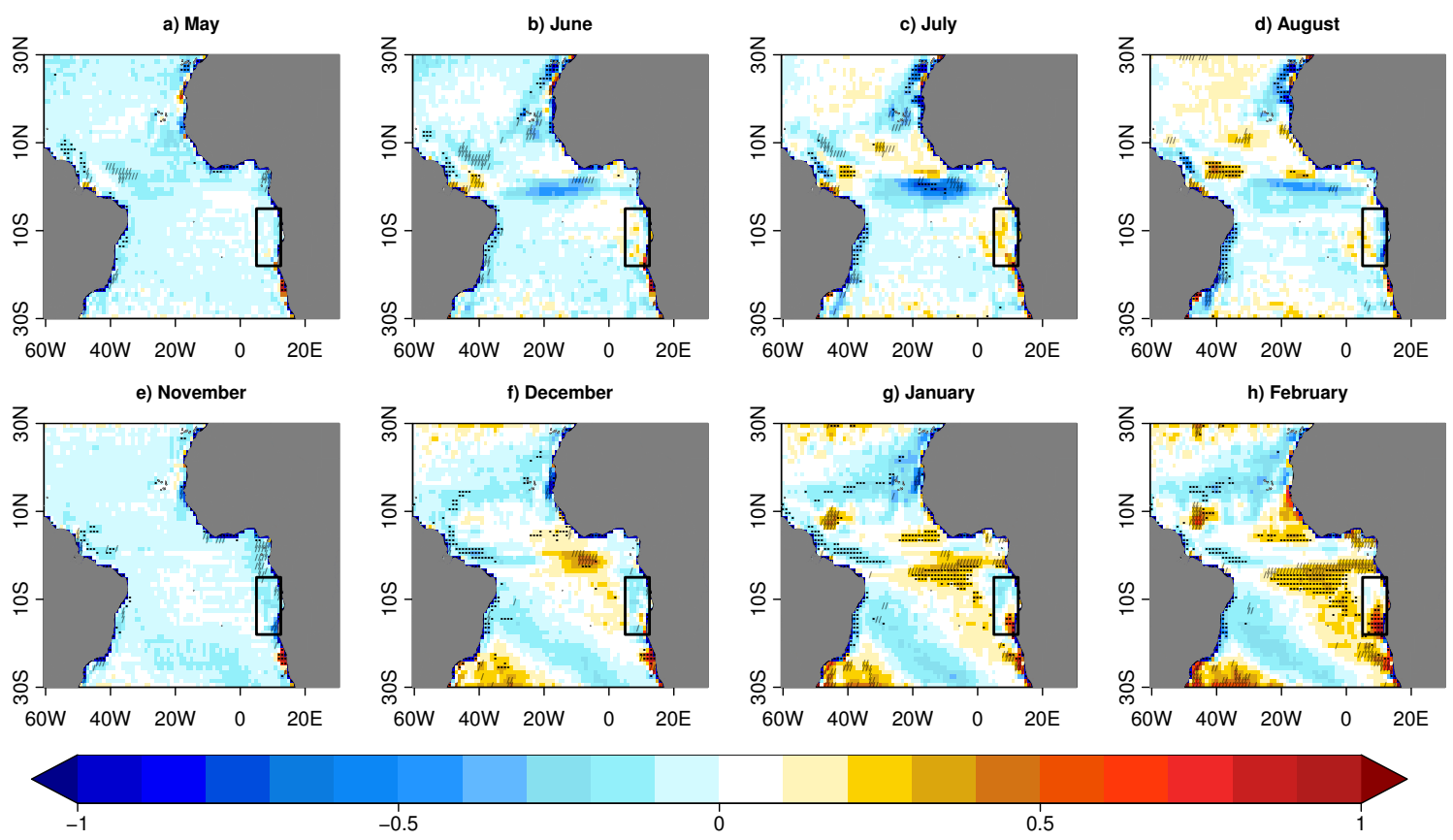

Figure 3: Difference in SST between the LR-Hind and HR-Hind (LR-Hind minus HR-hind). Dotted (dashed) areas indicate regions where the LR-Hind experiment has significantly larger (smaller) bias (at a 90\% confidence level) than HR-Hind (HadISST is used as a reference observational dataset). Please note that the colour levels correspond to half the ones used in Figs 1 and 2.

a) SST bias in summer

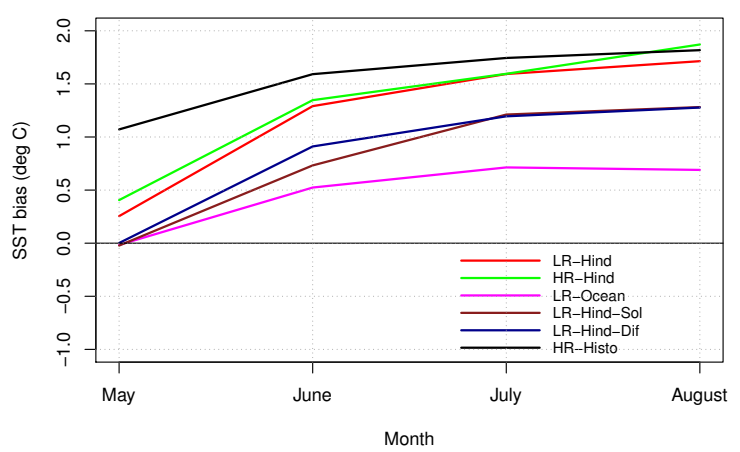

b) SST bias in winter

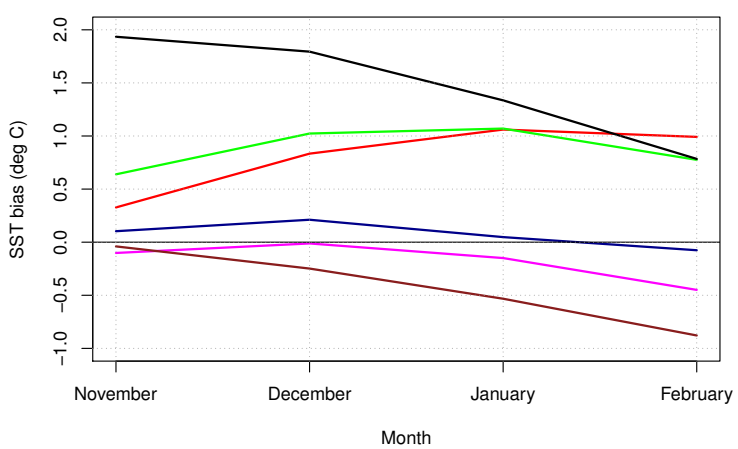

Figure 4: Forecast biases in SST (in ${ }^{\circ} \mathrm{C}$ ) in a) $\mathrm{CAB}$, for summer months (May-August), b) CAB, for winter months (November-February). The bias of the HR-Histo with respect to HadISST, for the corresponding months, but for the period of 1960-1999, is also shown. 
a) CAB, Summer, LR-Hind

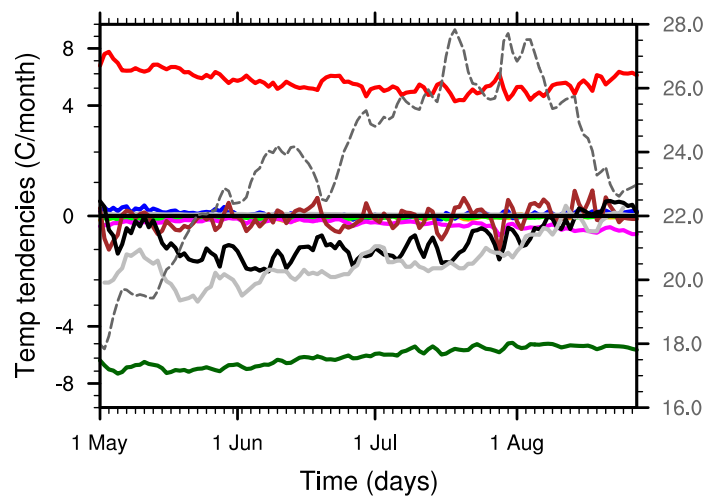

c) CAB, Summer, LR-Hind-Sol minus LR-Hind

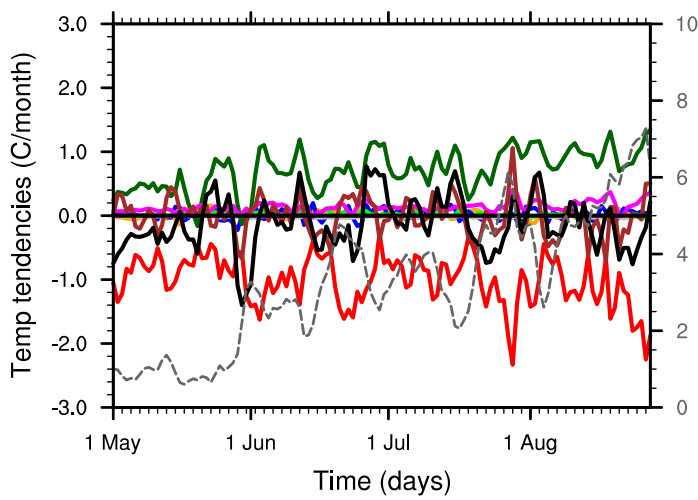

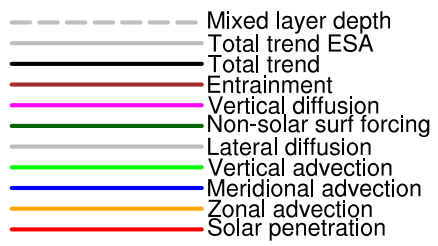

b) CAB, Winter, LR-Hind

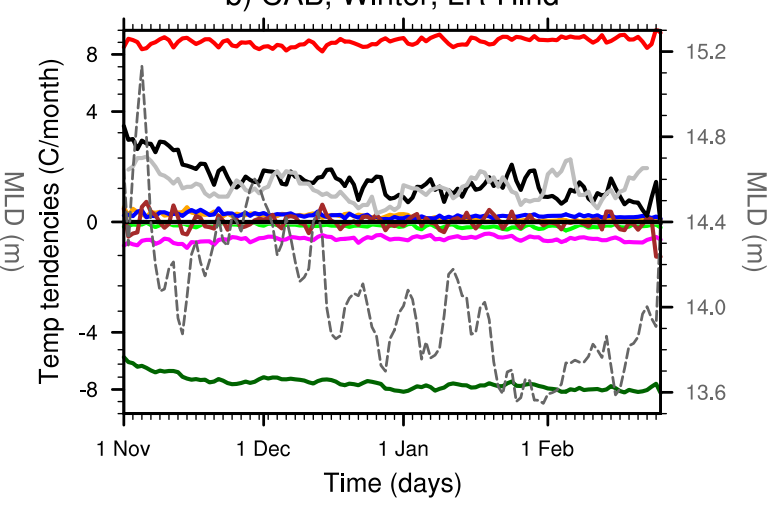

d) CAB, Winter, LR-Hind-Sol minus LR-Hind

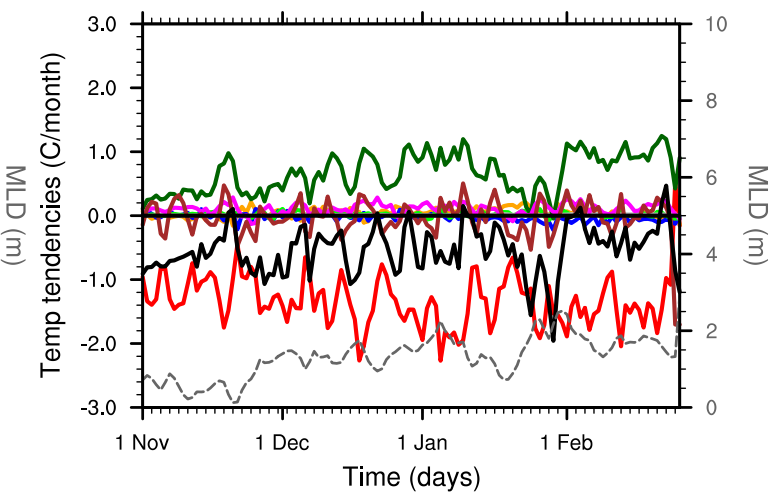

Figure 5: Daily mean temperature tendencies (in ${ }^{\circ} \mathrm{C} / \mathrm{month}$ ) of $\mathrm{Eq} 1$ (colored lines) and daily mean mixed layer depth where this tendencies are calculated (defined with a density criterion of $0.01 \mathrm{~kg} / \mathrm{m}^{3}$ compared to the density at $10 \mathrm{~m}$ depth, dashed grey line corresponding to values in right Y axis) in CAB for LR-Hind (top row) and the difference in tendencies LR-Hind-Sol minus LR-Hind (bottom row) for the period of May to August (panels a) and c)) and November to February (panels b) and d)). The total temperature tendency from ESA is also shown (grey line). Please note the irregular left $\mathrm{Y}$ axis in a) and $\mathrm{b}$ ). 

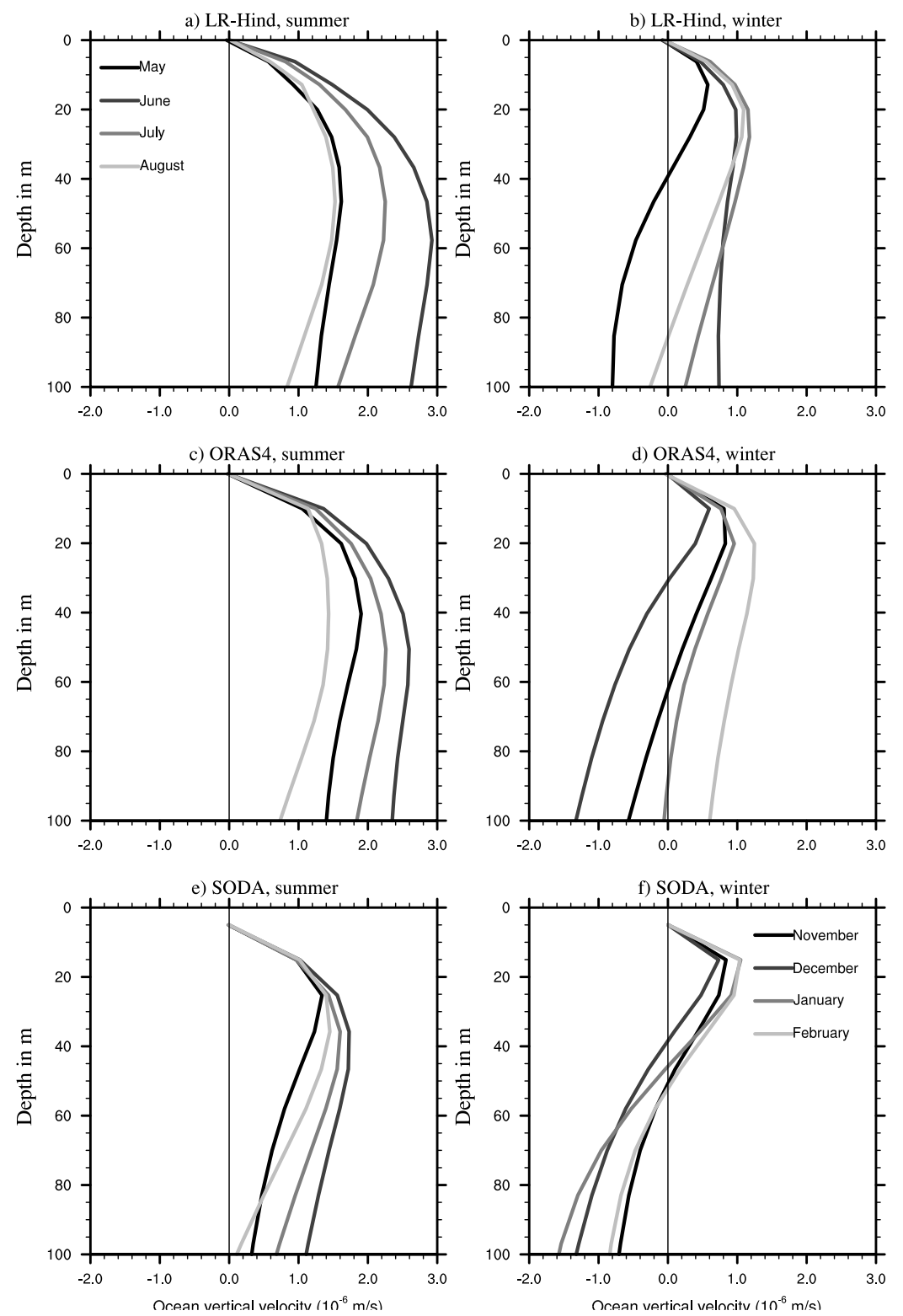

Figure 6: Monthly mean vertical velocities as a function of depth (in $10^{-6} \mathrm{~m} / \mathrm{s}$ ), area averaged over the CAB region, for LR-Hind (top row), ORAS4 reanalysis (middle) and SODA reanalysis (bottom row), for summer months (May-August, left) and winter months (November-February, right). Positive (negative) vertical velocities are upward (downward). 
a) LR-Hind, Summer

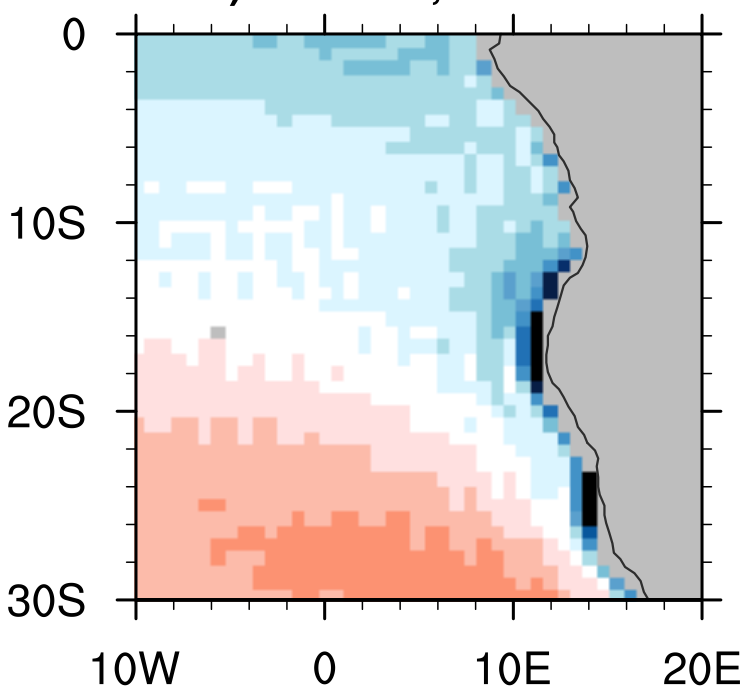

c) QuikSCAT, Summer

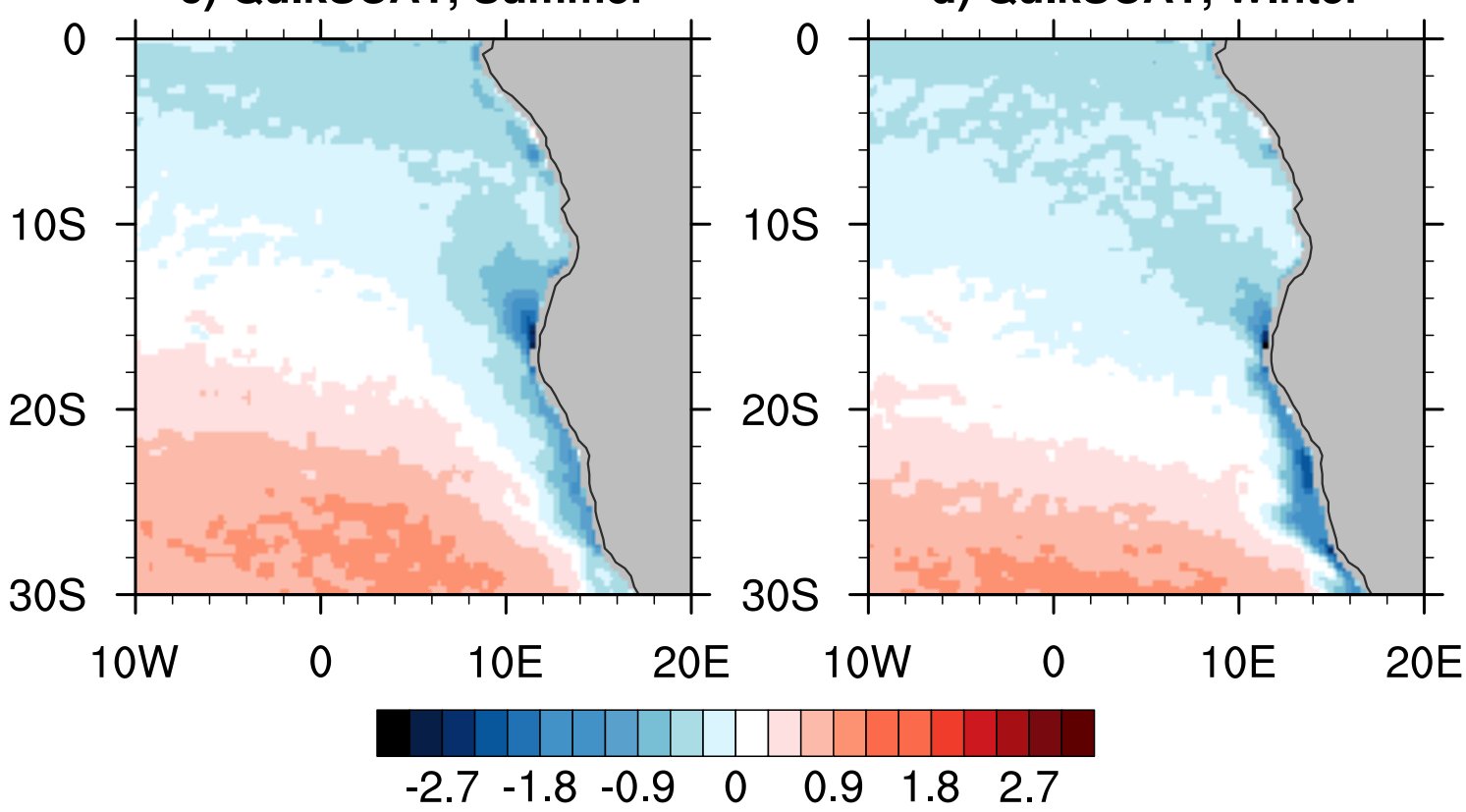

Figure 7: Seasonal mean windstress curl (in m/s per $100 \mathrm{~km}$ ) for LR-Hind (top row) and QuickSCAT data (bottom row), averaged over the summer months (May-August, left) and winter months (NovemberFebruary, right). Negative means counter-clockwise rotation, inducing upwelling and vice-versa. 
a) LR-Hind, Summer
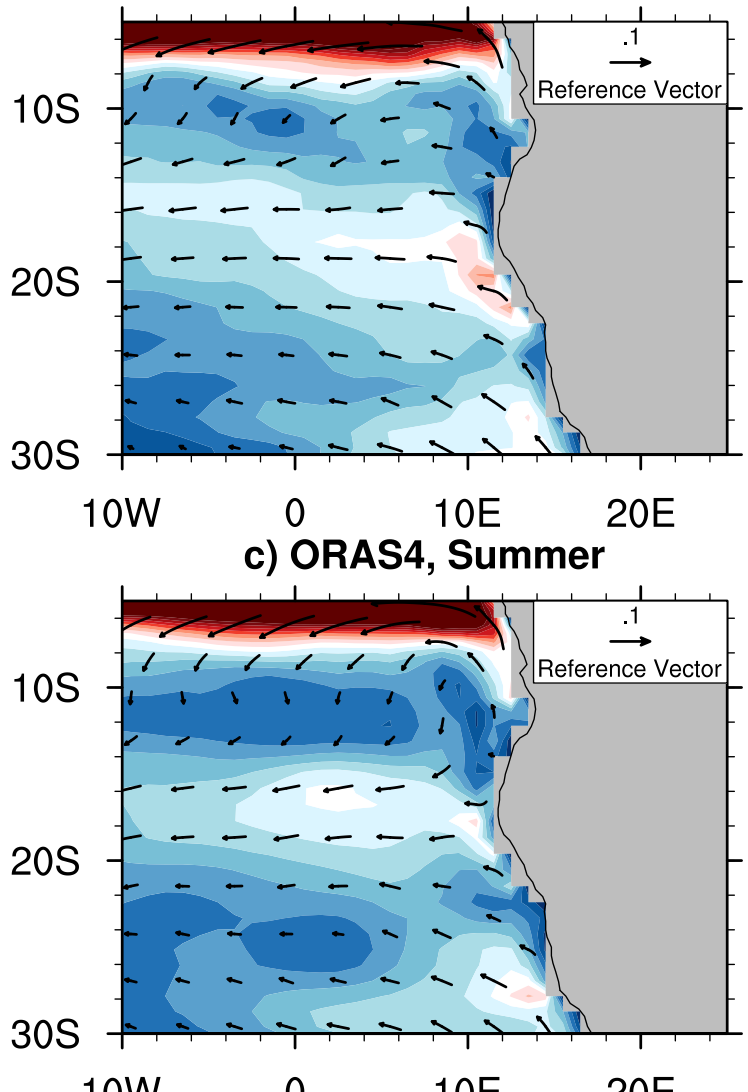

e) LR-Hind minus ORAS4, Summer b) LR-Hind, Winter
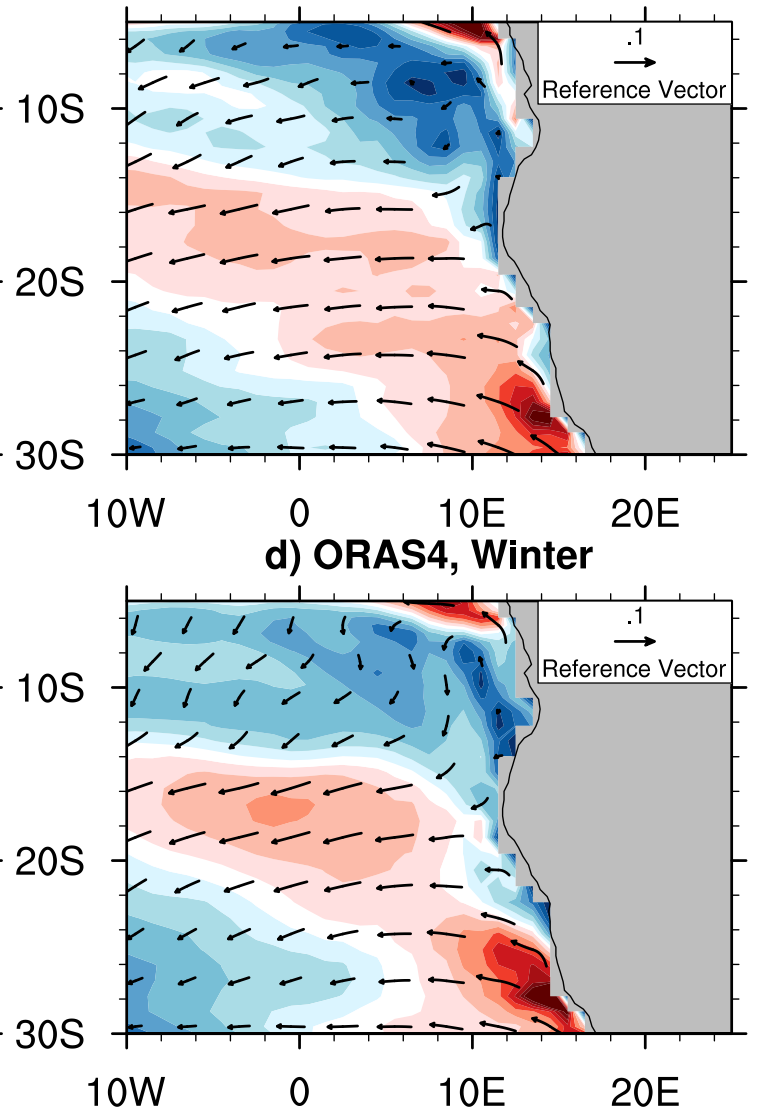

f) LR-Hind minus ORAS4, Winter

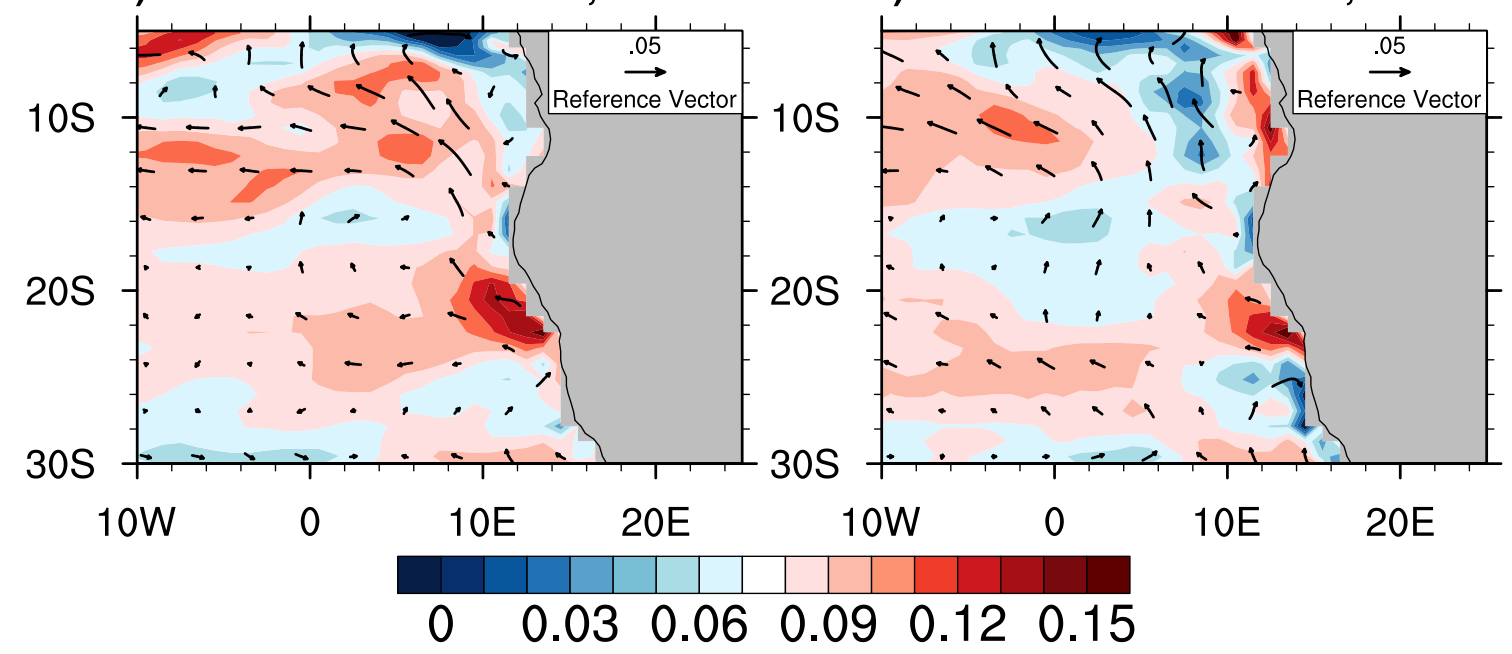

Figure 8: Ocean surface currents (vectors, in $\mathrm{m} / \mathrm{s}$ ) where contours show the currents magnitudes (in $\mathrm{m} / \mathrm{s}$ ), for summer (May-August, left) and winter (November-February, right), for LR-Hind (top) and ORAS4 (middle) and LR-Hind minus ORAS4 (bottom). 

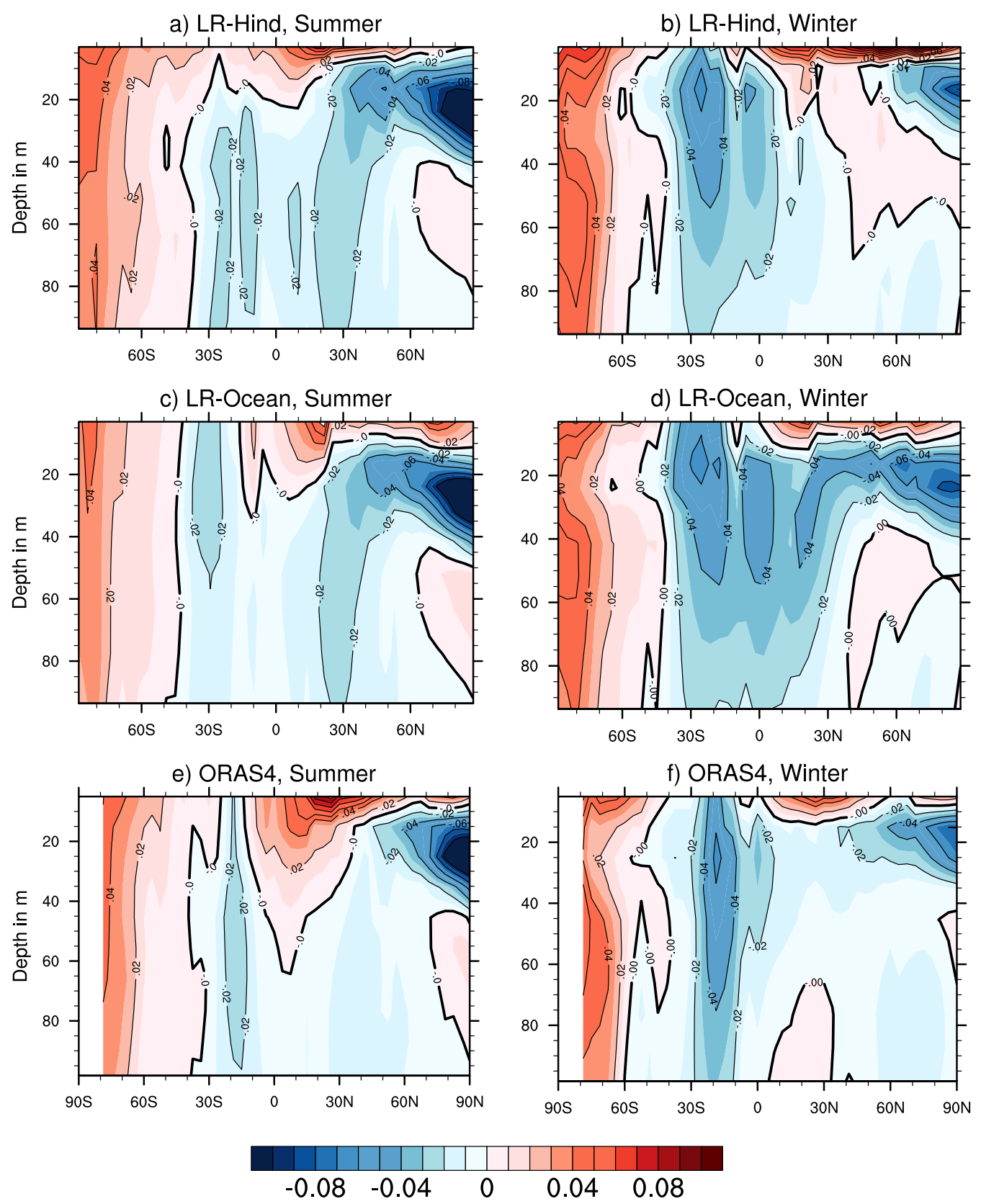

Figure 9: Meridional ocean velocities $v$ (in $\mathrm{m} / \mathrm{s}$, positive values are northward), averaged from the coast to 2 degrees offshore for LR-Hind (top), LR-Ocean (middle) and ORAS4 (bottom) averaged over the summer months (May-August, left) and winter months (November-February, right). Color contour intervals are 0.01 $\mathrm{m} / \mathrm{s}$, line contour intervals are $0.02 \mathrm{~m} / \mathrm{s}$. 
a) LR-Hind, May

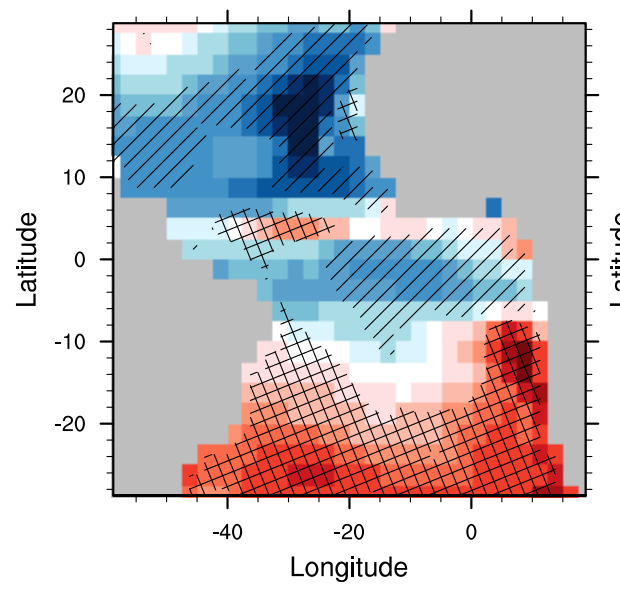

c) LR-Atm, May

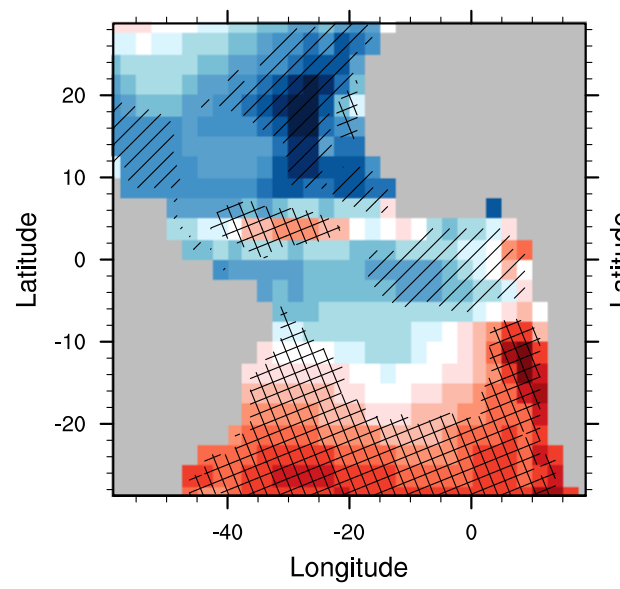

b) LR-Hind, November

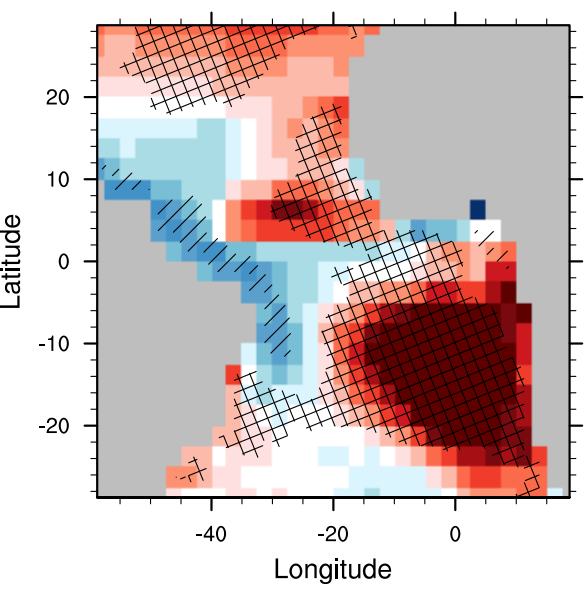

d) LR-Atm, November

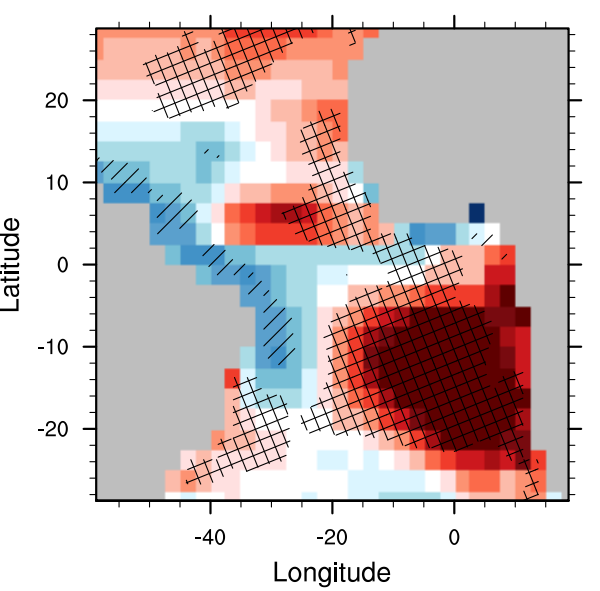

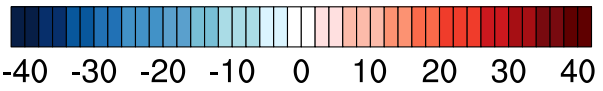

Figure 10: The colored contours denote the forecast biases in downward solar fluxes for the LR-Hind experiment with respect to TropFlux, for May and November. The hatched pattern denotes areas where the model has at least 5\% less total cloud fraction than observations, whereas the dashed pattern denotes areas where the model has at least 5\% more total cloud fraction then observations (cloud fraction is daytime only). The reference dataset for total cloud cover observations is ISCCP. 

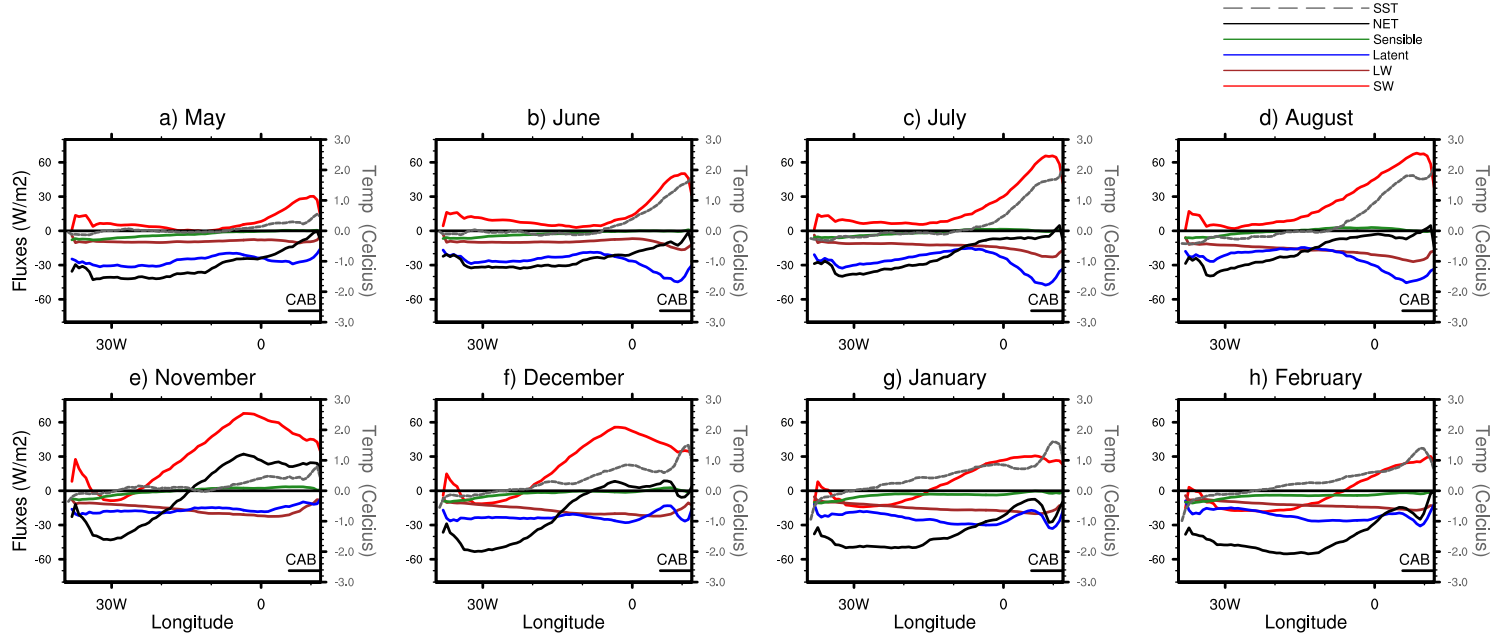

Figure 11: Forecast biases in the four components of the meridionally averaged (between $18^{\circ} \mathrm{S}-5^{\circ} \mathrm{S}$ ) surface heat fluxes (positive is downwards, units are $\mathrm{W} / \mathrm{m}^{2}$ ) for the LR-Hind experiment with respect to TropFlux. Sensible heat fluxes are shown in green, latent in blue, longwave in brown, shortwave in red, and net heat fluxes in black, for the the summer months (May-August) in the top row and winter months (November-February) in the bottom row. The grey line is the SST bias (with respect to HadISST), and its values are shown in the right $\mathrm{Y}$ axis.

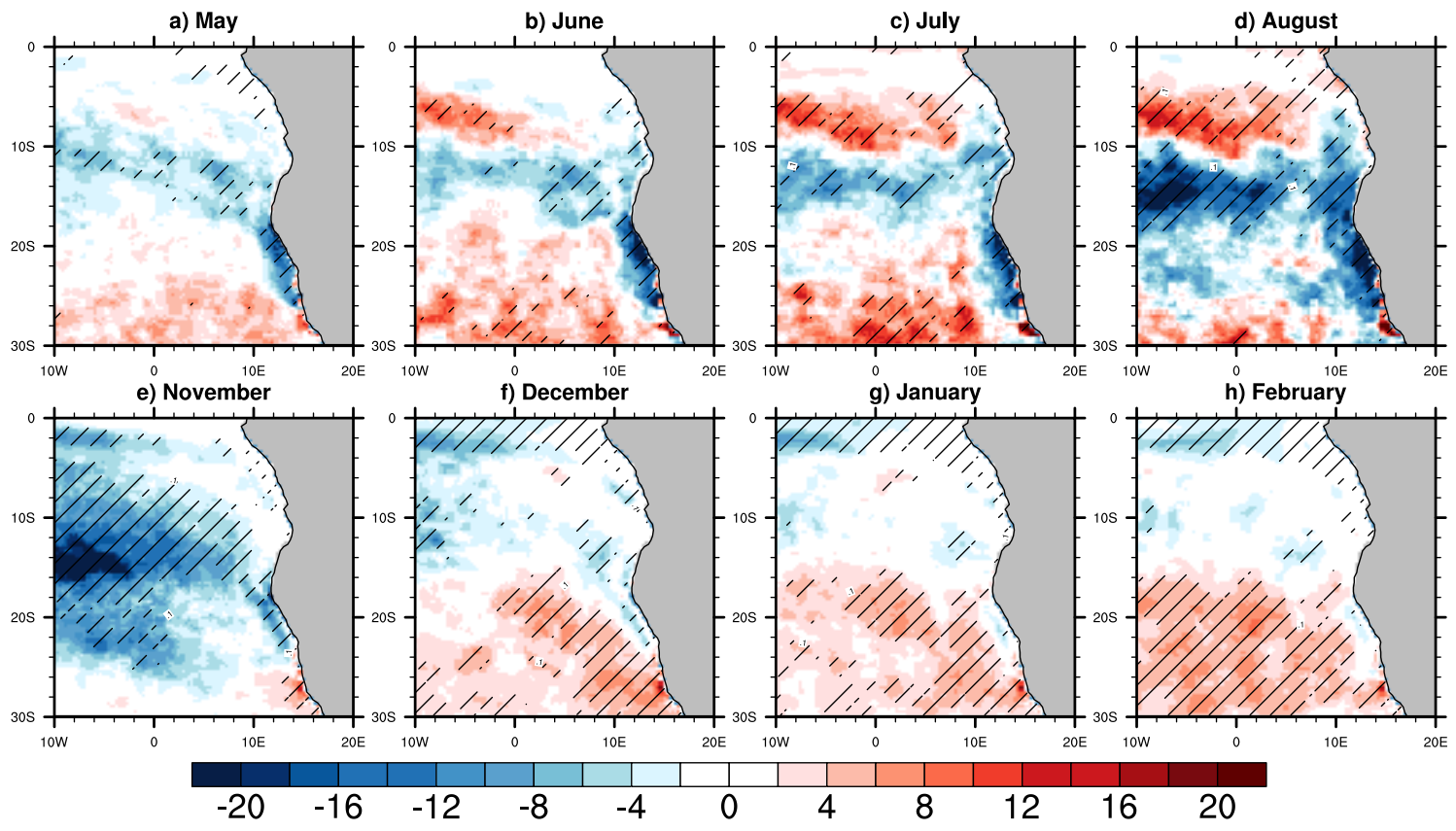

Figure 12: Forecast bias in OML depth (in $m$ ) for the HR-Hind experiment with respect to GLORYS. The bias is calculated as the difference between HR-Hind and GLORYS in their average over 17 years (19932009) for each forecast month. The summer months (May-August) are shown in the top row and the winter months (November to February) in the bottom row. Dashed values denote statistically siginificant changes based on a Student's t-test (at a $95 \%$ confidence level). 

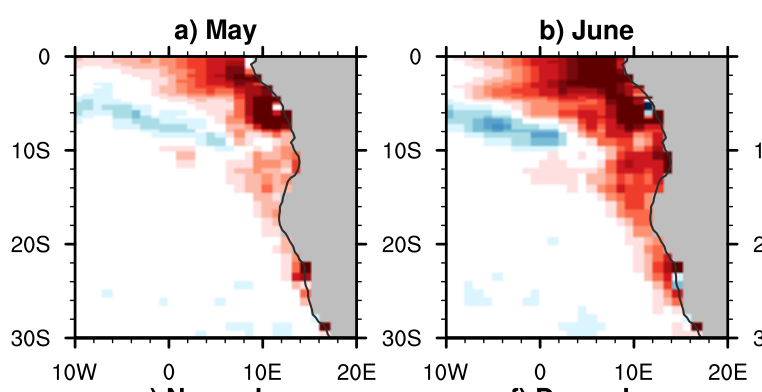

b) June
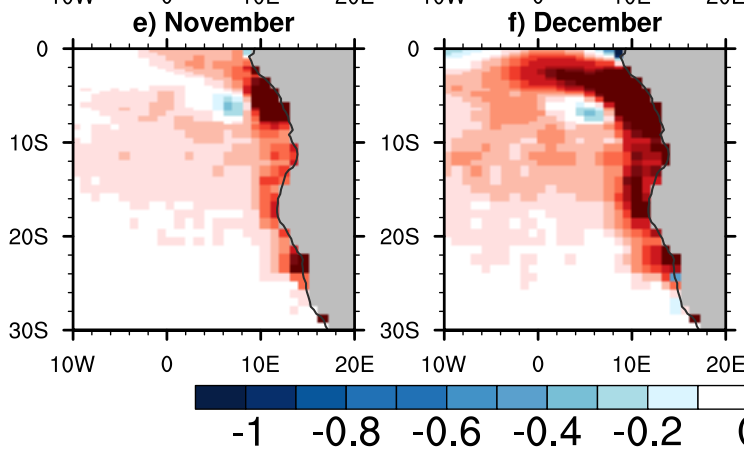

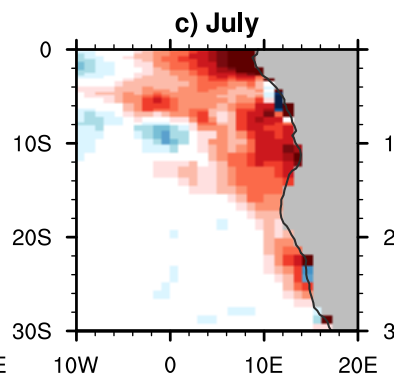

c) July

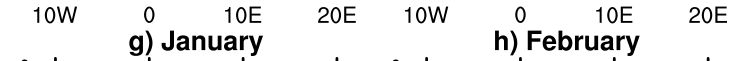

Figure 13: Forecast bias in potential density gradient of $\sigma_{0}$, defined as the difference between the $\sigma_{0}$ at $100 \mathrm{~m}$ minus $\sigma_{0}$ at sea surface (in $\mathrm{kg} / \mathrm{m}^{3}$ ) for the LR-Hind experiment with respect to GLORYS. The bias is calculated as the difference between HR-Hind and GLORYS in their average over 17 years (1993-2009) for each forecast month. The summer months (May-August) are shown in the top row and the winter months (November to February) in the bottom row. Positive (negative) values denote that LR-Hind is more (less) stable than GLORYS.

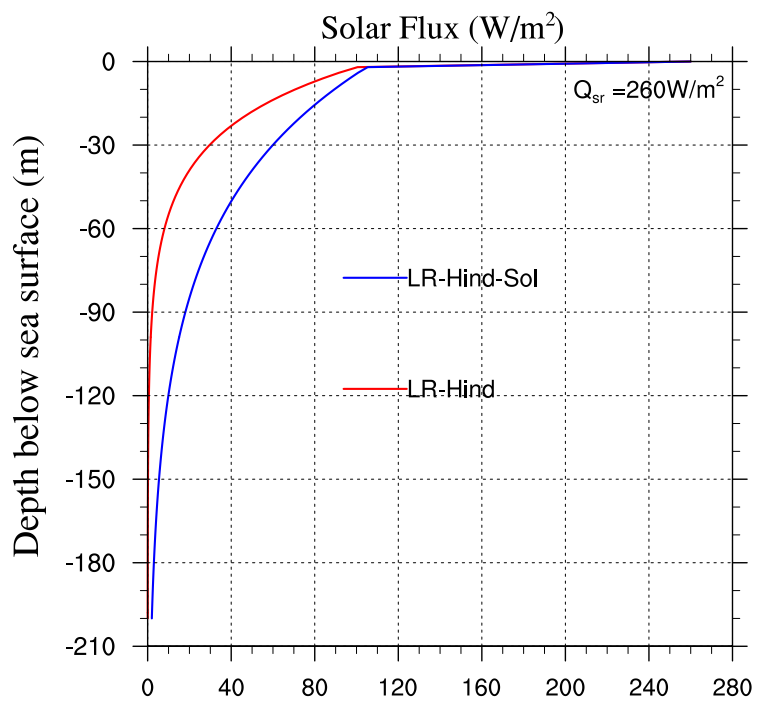

Figure 14: Vertical profiles of solar flux with depth (in $\mathrm{W} / \mathrm{m}^{2}$ ) for LR-Hind and LR-Hind-Sol, for a surface solar radiation of $Q_{s r}=260 \mathrm{~W} / \mathrm{m}^{2}$. 
May
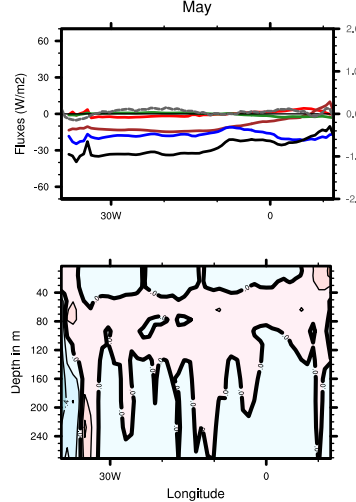

June
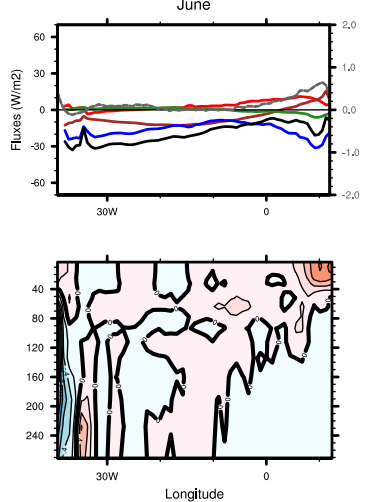

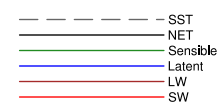

July
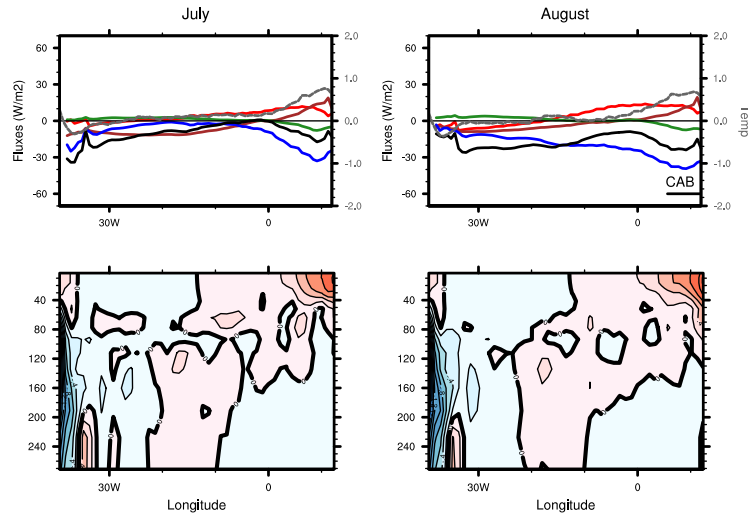

Figure 15: Forecast biases for the summer months (May-August), meridionally averaged between $18^{\circ} \mathrm{S}$ $5^{\circ} \mathrm{S}$, for the LR-Ocean experiment for (top row) the surface heat fluxes, with respect to TropFlux (positive is downwards, units are $\mathrm{W} / \mathrm{m}^{2}$ ). The LR-Ocean is forced by DFS4.3 (Table 1), therefore the biases in solar fluxes are DFS4.3 biases. The grey line is the SST bias (with respect to HadISST), and its values are shown in the right $\mathrm{Y}$ axis, in ${ }^{\circ} \mathrm{C}$. Bottom row: the potential ocean temperature in the top $300 \mathrm{~m}$, with respect to GLORYS, in ${ }^{\circ} \mathrm{C}$. Contour interval is $0.2^{\circ} \mathrm{C}$. 


\section{References}

Axell, L. B., 2002: Wind-driven internal waves and langmuir circulations in a numerical ocean model of the southern baltic sea. Journal of Geophysical Research: Oceans, 107 (C11).

Balmaseda, M., et al., 2009: Ocean initialization for seasonal forecasts. Oceanography, 22 (3), 154-159, URL http://www.researchgate.net/publication/ 45404088\{_\}Ocean\{_\}Initialization\{_\}for\{_\}Seasonal\{_\}Forecasts / file/79e41506a3470981d1.pdf.

Balmaseda, M. A., K. Mogensen, and A. T. Weaver, 2013: Evaluation of the ECMWF ocean reanalysis system ORAS4. Quarterly Journal of the Royal Meteorological Society, 139 (674), 1132-1161, doi:10.1002/qj.2063, URL http://doi . wiley.com/10. 1002/qj. 2063.

Beckmann, A. and R. Döscher, 1997: A method for improved representation of dense water spreading over topography in geopotential-coordinate models. J. Phys. Oceanogr., 27, 581-591, doi:10.1175/1520-0485(1997)027<0581:AMFIRO>2.0.CO;2.

Blanke, B. and P. Delecluse, 1993: Variability of the tropical atlantic ocean simulated by a general circulation model with two different mixed-layer physics. J. Phys. Oceanogr., 23, 1363-1388, doi:10.1175/1520-0485(1993)023\$<\$1363:vottao\$>\$2.0.co;2.

Bouillon, S., M. A. M. Maqueda, V. Legat, and T. Fichefet, 2009: Sea ice model formulated on Arakawa B and C grids. Ocean Modelling, 27, 174-184.

Brierley, C. M., M. Collins, and A. J. Thorpe, 2008: The impact of perturbations to ocean-model parameters on climate and climate change in a coupled model. Climate Dynamics, 34 (2-3), 325-343, doi:10.1007/s00382-008-0486-3, URL http://link. springer.com/10.1007/s00382-008-0486-3.

Brodeau, L., B. Barnier, A.-M. Treguier, T. Penduff, and S. Gulev, 2010: An era40-based atmospheric forcing for global ocean circulation models. Ocean Modelling, 31 (3), 88104.

Caron, L.-P., C. G. Jones, and F. Doblas-Reyes, 2014: Multi-year prediction skill of atlantic hurricane activity in cmip5 decadal hindcasts. Climate dynamics, 42 (9-10), 2675-2690.

Carslaw, K. S., et al., 2013: Large contribution of natural aerosols to uncertainty in indirect forcing. Nature, 503 (7474), 67-71, doi:10.1038/nature12674, URL http: //www.ncbi.nlm.nih.gov/pubmed/24201280.

Carton, J. A. and B. S. Giese, 2008: A reanalysis of ocean climate using simple ocean data assimilation (soda). Monthly Weather Review, 136 (8), 2999-3017.

Chowdary, J. S., A. Parekh, S. Ojha, C. Gnanaseelan, and R. Kakatkar, 2016: Impact of upper ocean processes and air-sea fluxes on seasonal SST biases over the tropical 
Indian Ocean in the NCEP Climate Forecasting System. International Journal of Climatology, 36 (1), 188-207, doi:10.1002/joc.4336, URL http: //doi . wiley . com/10. $1002 /$ joc 4336 .

Christian, J. R. and R. Murtugudde, 2003: Tropical atlantic variability in a coupled physical-biogeochemical ocean model. Deep Sea Research Part II: Topical Studies in Oceanography, 50 (22), 2947-2969.

Colas, F., J. C. McWilliams, X. Capet, and J. Kurian, 2012: Heat balance and eddies in the peru-chile current system. Climate dynamics, 39 (1-2), 509-529.

Crane, T. a., C. Roncoli, J. Paz, N. Breuer, K. Broad, K. T. Ingram, and G. Hoogenboom, 2010: Forecast Skill and Farmers' Skills: Seasonal Climate Forecasts and Agricultural Risk Management in the Southeastern United States. Weather, Climate, and Society, 2 (1), 44-59, doi:10.1175/2009WCAS1006.1.

D'Asaro, E. A., 1985: The energy flux from the wind to near-inertial motions in the surface mixed layer. Journal of Physical Oceanography, 15 (8), 1043-1059.

De Felice, M., A. Alessandri, and F. Catalano, 2015: Seasonal climate forecasts for medium-term electricity demand forecasting. Applied Energy, 137, 435-444, doi: 10.1016/j.apenergy.2014.10.030.

Dee, D. P., et al., 2011: The ERA-Interim reanalysis: configuration and performance of the data assimilation system. Quarterly Journal of the Royal Meteorological Society, 137 (656), 553-597, URL http: //centaur. reading . ac . uk/24937/.

Deser, C., M. A. Alexander, and M. S. Timlin, 2003: Understanding the persistence of sea surface temperature anomalies in midlatitudes. Journal of Climate, 16 (1), 57-72.

Doblas-Reyes, F., R. Hagedorn, and T. Palmer, 2006: Developments in dynamical seasonal forecasting relevant to agricultural management. Climate Research, 33 (1), 19.

Doblas-Reyes, F. J., J. García-Serrano, F. Lienert, A. P. Biescas, and L. R. L. Rodrigues, 2013a: Seasonal climate predictability and forecasting: Status and prospects. Wiley Interdisciplinary Reviews: Climate Change, 4 (4), 245-268, doi:10.1002/wcc.217, URL http://doi.wiley.com/10.1002/wcc. 217.

Doblas-Reyes, F. J., et al., 2013b: Initialized near-term regional climate change prediction. Nature communications, 4, 1715, doi:10.1038/ncomms2704, URL http://www.pubmedcentral.nih.gov/articlerender.fcgi?artid= $3644073\{\&\}$ tool=pmcentrez $\{\&\}$ rendertype=abstract.

Du, H., F. J. Doblas-Reyes, J. García-Serrano, V. Guemas, Y. Soufflet, and B. Wouters, 2012: Sensitivity of decadal predictions to the initial atmospheric and oceanic perturbations. Climate Dynamics, 39 (7), 2013-2023, doi:10.1007/s00382-011-1285-9, URL http://dx.doi.org/10.1007/s00382-011-1285-9.

Emanuel, K., F. Fondriest, and J. Kossin, 2012: Potential economic value of seasonal hurricane forecasts. Weather, Climate, and Society, 4 (2), 110-117. 
Ferry, N., L. Parent, G. Garric, B. Barnier, and N. C. Jourdain, 2010: Mercator global eddy permitting ocean reanalysis glorys1v1: Description and results. Mercator-Ocean Quarterly Newsletter, 36, 15-27.

Fichefet, T. and M. Maqueda, 1997: Sensitivity of a global sea ice model to the treatment of ice thermodynamics and dynamics. Journal of Geophysical Research: Oceans (1978-2012), 102 (C6), 12 609-12646.

Forbes, R. M., A. M. Tompkins, and A. Untch, 2011: A New Prognastic Bulk Microphysics Scheme for the IFS. European Centre for Medium-Range Weather Forecasts.

Garcia-Morales, M. B. and L. Dubus, 2007: Forecasting precipitation for hydroelectric power management: how to exploit GCM's seasonal ensemble forecasts. International Journal of Climatology, 27 (12), 1691, doi:10.1002/joc.1608.

García-Serrano, J., F. Doblas-Reyes, R. Haarsma, and I. Polo, 2013: Decadal prediction of the dominant west african monsoon rainfall modes. Journal of Geophysical Research: Atmospheres, 118 (11), 5260-5279.

Garrett, C., 2001: What is the "near-inertial" band and why is it different from the rest of the internal wave spectrum? Journal of Physical Oceanography, 31 (4), 962-971.

Gaspar, P., Y. Grégoris, and J.-M. Lefevre, 1990: A simple eddy kinetic energy model for simulations of the oceanic vertical mixing: Tests at station papa and long-term upper ocean study site. Journal of Geophysical Research: Oceans, 95 (C9), 16 179-16 193.

Gent, P. R. and J. C. McWilliams, 1990: Isopycnal mixing in ocean circulation models. J. Phys. Oceanogr., 20, 150-155, doi:10.1175/1520-0485(1990)020<0150:IMIOCM> 2.0.CO;2.

Giordani, H., G. Caniaux, and A. Voldoire, 2013: Intraseasonal mixed-layer heat budget in the equatorial atlantic during the cold tongue development in 2006. Journal of Geophysical Research: Oceans, 118 (2), 650-671.

Grodsky, S. A., J. A. Carton, S. Nigam, and Y. M. Okumura, 2012: Tropical atlantic biases in ccsm4. Journal of Climate, 25 (11), 3684-3701.

Haman, K. E., S. P. Malinowski, M. J. Kurowski, H. Gerber, and J.-L. Brenguier, 2007: Small scale mixing processes at the top of a marine stratocumulus-a case study. Quarterly Journal of the Royal Meteorological Society, 133 (622), 213-226.

Hastenrath, S. and P. Lamb, 1978: On the dynamics and climatology of surface flow over the equatorial oceans. Tellus, 30 (5), 436-448.

Hawkins, E. and R. Sutton, 2009: The Potential to Narrow Uncertainty in Regional Climate Predictions. Bulletin of the American Meteorological Society, 90 (8), 10951107, doi:10.1175/2009BAMS2607.1, URL http://journals.ametsoc.org/doi/ abs/10.1175/2009BAMS2607.1.

Hazeleger, W. and R. J. Haarsma, 2005: Sensitivity of tropical atlantic climate to mixing in a coupled ocean-atmosphere model. Climate dynamics, 25 (4), 387-399. 
Hazeleger, W., et al., 2012: EC-earth V2.2: Description and validation of a new seamless earth system prediction model. Climate Dynamics, 39 (11), 2611-2629.

Hibler, W. D., 1979: A dynamic thermodynamic sea ice model. J. Phys. Oceanogr., 9, 815-846.

Hieronymus, M. and J. Nycander, 2013: The budgets of heat and salinity in NEMO. Ocean Modelling, 67, 28-38, doi:10.1016/j.ocemod.2013.03.006, URL http:// linkinghub.elsevier.com/retrieve/pii/S1463500313000462.

Hourdin, F., et al., 2013: Impact of the lmdz atmospheric grid configuration on the climate and sensitivity of the ipsl-cm5a coupled model. Climate Dynamics, 40 (9-10), 21672192.

Huang, B., Z.-Z. Hu, and B. Jha, 2007: Evolution of model systematic errors in the tropical atlantic basin from coupled climate hindcasts. Climate dynamics, 28 (7-8), 661-682.

Huang, B., P. H. Stone, A. P. Sokolov, and I. V. Kamenkovich, 2003: Ocean heat uptake in transient climate change: Mechanisms and uncertainty due to subgrid-scale eddy mixing. Journal of climate, 16 (20), 3344-3356.

Jarre, A., et al., 2015: Synthesis: Climate effects on biodiversity, abundance and distribution of marine organisms in the Benguela. Fisheries Oceanography, 24 (S1), 122-149, doi:10.1111/fog.12086.

Jewson, S., et al., 2008: 5 year prediction of the number of hurricanes which make us landfall. Hurricanes and Climate Change, 73-99.

Jin, X. and R. A. Weller, 2008: Multidecade global flux datasets from the objectively analyzed air-sea fluxes (oaflux) project: Latent and sensible heat fluxes, ocean evaporation, and related surface meteorological variables lisan yu. OAFlux Project Tech. Rep. OA-2008-01., 74.

Jouanno, J., F. Marin, Y. Du Penhoat, J. Sheinbaum, and J.-M. Molines, 2011: Seasonal heat balance in the upper $100 \mathrm{~m}$ of the equatorial atlantic ocean. Journal of Geophysical Research: Oceans, 116 (C9).

Jung, T., et al., 2012: High-resolution global climate simulations with the ECMWF model in project athena: Experimental design, model climate, and seasonal forecast skill. Journal of Climate, 25 (9), 3155-3172, doi:10.1175/JCLI-D-11-00265.1.

Keenlyside, N. S., H. Ding, and M. Latif, 2013: Potential of equatorial Atlantic variability to enhance El Niño prediction. Geophysical Research Letters, 40 (10), 2278-2283, doi: 10.1002/grl.50362.

Knutti, R., G. A. Meehl, M. R. Allen, and D. A. Stainforth, 2006: Constraining climate sensitivity from the seasonal cycle in surface temperature. Journal of Climate, 19 (17), $4224-4233$. 
Kucharski, F., A. Bracco, J. H. Yoo, and F. Molteni, 2008: Atlantic forced component of the Indian monsoon interannual variability. Geophysical Research Letters, 35 (4), 1-5, doi:10.1029/2007GL033037.

Kumar, B. P., J. Vialard, M. Lengaigne, V. Murty, and M. McPhaden, 2012: Tropflux: airsea fluxes for the global tropical oceans - description and evaluation. Climate dynamics, 38 (7-8), 1521-1543.

Large, W. and G. Danabasoglu, 2006: Attribution and impacts of upper-ocean biases in ccsm3. Journal of Climate, 19 (11), 2325-2346.

Lass, H., M. Schmidt, V. Mohrholz, and G. Nausch, 2000: Hydrographic and current measurements in the area of the angola-benguela front. Journal of Physical Oceanography, 30 (10), 2589-2609.

Ledwell, J., E. Montgomery, K. Polzin, St. Laurent LC, R. Schmitt, and J. Toole, 2000: Evidence for enhanced mixing over rough topography in the abyssal ocean. Nature, 403 (6766), 179-82, doi:10.1038/35003164, URL http: //www.ncbi.nlm.nih.gov/ pubmed/10646599.

Lengaigne, M., C. Menkes, O. Aumont, T. Gorgues, L. Bopp, J.-M. André, and G. Madec, 2007: Influence of the oceanic biology on the tropical pacific climate in a coupled general circulation model. Climate Dynamics, 28 (5), 503-516.

Lenschow, D. H., M. Zhou, X. Zeng, L. Chen, and X. Xu, 2000: Measurements of finescale structure at the top of marine stratocumulus. Boundary-layer meteorology, 97 (2), 331-357.

Lindborg, E. and G. Brethouwer, 2008: Vertical dispersion by stratified turbulence. Journal of Fluid Mechanics, 614, 303-314.

Ma, H.-Y., et al., 2014: On the correspondence between mean forecast errors and climate errors in cmip5 models. Journal of Climate, 27 (4), 1781-1798.

Maclachlan, C., et al., 2014: Global Seasonal forecast system version 5 (GloSea5): A high-resolution seasonal forecast system. Quarterly Journal of the Royal Meteorological Society, 5, doi:10.1002/qj.2396.

Madec, G., 2008: Nemo ocean engine.

Manabe, S. and R. J. Stouffer, 1996: Low-frequency variability of surface air temperature in a 1000-year integration of a coupled atmosphere-ocean-land surface model. Journal of Climate, 9 (2), 376-393.

Mellor, G. and A. Blumberg, 2004: Wave breaking and ocean surface layer thermal response. Journal of physical oceanography, 34 (3), 693-698.

Merchant, C. J., et al., 2014: Sea surface temperature datasets for climate applications from phase 1 of the european space agency climate change initiative (sst cci). Geoscience Data Journal, 1 (2), 179-191. 
Monger, B., C. McClain, and R. Murtugudde, 1997: Seasonal phytoplankton dynamics in the eastern tropical atlantic. Journal of Geophysical Research: Oceans, 102 (C6), $12389-12411$.

Morcrette, J., H. Barker, J. Cole, M. Iacono, and R. Pincus, 2008: Impact of a new radiation package, mcrad, in the ecmwf integrated forecasting system. Monthly Weather Review, 136 (12), 4773-4798.

Morel, A., 1988: Optical modeling of the upper ocean in relation to its biogenous matter content(case i waters). Journal of Geophysical Research, 93 (10), 749-10.

Moum, J. N., D. R. Caldwell, and C. A. Paulson, 1989: Mixing in the equatorial surface layer and thermocline. Journal of Geophysical Research: Oceans, 94 (C2), 2005-2022.

Nash, J. D., E. Kunze, J. M. Toole, and R. W. Schmitt, 2004: Internal tide reflection and turbulent mixing on the continental slope. Journal of Physical Oceanography, 34 (5), $1117-1134$.

Patricola, C. M., M. Li, Z. Xu, P. Chang, R. Saravanan, and J.-S. Hsieh, 2012: An investigation of tropical atlantic bias in a high-resolution coupled regional climate model. Climate dynamics, 39 (9-10), 2443-2463.

Peterson, R. G. and L. Stramma, 1991: Upper-level circulation in the south atlantic ocean. Progress in oceanography, 26 (1), 1-73.

Planton, Y., 2015: Sources de la variabilité interannuelle de la langue d'eau froide Atlantique. Ph.D. thesis, Université Toulouse III Paul Sabatier.

Polzin, K. L. and E. Firing, 1997: Estimates of diapycnal mixing using ladep and ctd data from i8s. International WOCE Newsletter, 29, 39-42.

Prodhomme, C., F. Doblas-Reyes, O. Bellprat, and E. Dutra, 2015: Impact of land-surface initialization on sub-seasonal to seasonal forecasts over Europe. Climate Dynamics, doi:10.1007/s00382-015-2879-4, URL http://link.springer.com/10.1007/ s00382-015-2879-4.

Qu, X., A. Hall, S. A. Klein, and P. M. Caldwell, 2014: On the spread of changes in marine low cloud cover in climate model simulations of the 21 st century. Climate dynamics, 42 (9-10), 2603-2626.

Rayner, N. A., 2003: Global analyses of sea surface temperature, sea ice, and night marine air temperature since the late nineteenth century. Journal of Geophysical Research, 108 (D14), 4407, doi:10.1029/2002JD002670, URL http://doi.wiley.com/10. 1029/2002JD002670.

Richter, I., 2015: Climate model biases in the eastern tropical oceans: causes, impacts and ways forward. Wiley Interdisciplinary Reviews: Climate Change, 6 (3), 345-358, doi:10.1002/wcc.338, URL http://doi . wiley.com/10.1002/wcc. 338. 
Richter, I. and S. P. Xie, 2008: On the origin of equatorial Atlantic biases in coupled general circulation models. Climate Dynamics, 31 (5), 587-598, doi:10.1007/ s00382-008-0364-z.

Risien, C. M. and D. B. Chelton, 2008: A global climatology of surface wind and wind stress fields from eight years of quikscat scatterometer data. Journal of Physical Oceanography, 38 (11), 2379-2413.

Rodríguez-Fonseca, B., I. Polo, J. García-Serrano, T. Losada, E. Mohino, C. R. Mechoso, and F. Kucharski, 2009: Are Atlantic Niños enhancing Pacific ENSO events in recent decades? Geophysical Research Letters, 36 (20), L20705, doi:10.1029/ 2009GL040048.

Roehrig, R., D. Bouniol, F. Guichard, F. D. Hourdin, and J.-L. L. Redelsperger, 2013: The Present and Future of the West African Monsoon: A Process-Oriented Assessment of CMIP5 Simulations along the AMMA Transect. Journal of Climate, 26, 6471-6505, doi:10.1175/JCLI-D-12-00505.1, URL http://journals.ametsoc.org/doi/abs/ 10.1175/JCLI-D-12-00505.1.

Rossow, W. B., I. O. Commission, et al., 1996: International Satellite Cloud Climatology Project (ISCCP): documentation of new cloud datasets. NASA Goddard Space Flight Center.

Sakamoto, T. T., et al., 2012: MIROC4h - A New High-Resolution Atmosphere-Ocean Coupled General Circulation Model. Journal of the Meteorological Society of Japan, 90 (3), 325-359, doi:10.2151/jmsj.2012-301.

Saravanan, R. and P. Chang, 2000: Interaction between tropical atlantic variability and el nino-southern oscillation. Journal of Climate, 13 (13), 2177-2194.

Semtner, A. J., 1976: A model for the thermodynamic growth of sea ice in numerical investigations of climate. J. Phys. Ocean., 6, 379-389.

Sherwood, S. C., S. Bony, and J.-L. Dufresne, 2014: Spread in model climate sensitivity traced to atmospheric convective mixing. Nature, 505 (7481), 37-42.

Small, R. J., E. Curchitser, K. Hedstrom, B. Kauffman, and W. G. Large, 2015: The benguela upwelling system: Quantifying the sensitivity to resolution and coastal wind representation in a global climate model*. Journal of Climate, 28 (23), 9409-9432.

Song, Z., S.-K. Lee, C. Wang, B. P. Kirtman, and F. Qiao, 2015: Contributions of the atmosphere-land and ocean-sea ice model components to the tropical atlantic sst bias in cesm1. Ocean Modelling, 96, 280-290.

Soret, A., N. Gonzalez, V. Torralba, N. Cortesi, M. Turco, and F. J. Doublas-Reyes, 2016: Climate predictions for vineyard management (april 10-13, 2016, burdeaux, france).

Stainforth, D. a., et al., 2005: Uncertainty in predictions of the climate response to rising levels of greenhouse gases. Nature, 433 (7024), 403-6, doi:10.1038/nature03301, URL http://www.ncbi.nlm.nih.gov/pubmed/15674288. 
Sterl, A., et al., 2012: A look at the ocean in the EC-Earth climate model. Climate Dynamics, 39, 2631-2657, doi:10.1007/s00382-011-1239-2.

Stevens, B., et al., 2005: Evaluation of large-eddy simulations via observations of nocturnal marine stratocumulus. Monthly weather review, 133 (6), 1443-1462.

Sultan, B., C. Baron, M. Dingkuhn, B. Sarr, and S. Janicot, 2005: Agricultural impacts of large-scale variability of the West African monsoon. Agricultural and Forest Meteorology, 128 (1-2), 93-110, doi:10.1016/j.agrformet.2004.08.005.

Terray, P., S. Masson, C. Prodhomme, M. K. Roxy, and K. P. Sooraj, 2015: Impacts of Indian and Atlantic oceans on ENSO in a comprehensive modeling framework. Climate Dynamics, doi:10.1007/s00382-015-2715-x, URL http: //link. springer . com/10. $1007 / \mathrm{s} 00382-015-2715-\mathrm{x}$.

Tompkins, A. M. and F. di Giuseppe, 2015: Potential predictability of malaria in Africa using ECMWF monthly and seasonal climate forecasts. Journal of Applied Meteorology and Climatology, 54 (3), 521-540, doi:10.1175/JAMC-D-14-0156.1.

Toniazzo, T. and S. Woolnough, 2013: Development of warm SST errors in the southern tropical Atlantic in CMIP5 decadal hindcasts. Climate Dynamics, doi:10.1007/s00382-013-1691-2, URL http://link.springer.com/10.1007/ s00382-013-1691-2.

Toole, J. M., R. W. Schmitt, and K. L. Polzin, 1994: Estimates of diapycnal mixing in the abyssal ocean. Science (New York, N.Y.), 264 (5162), 1120-3, doi:10.1126/science.264. 5162.1120, URL http://www.ncbi.nlm.nih.gov/pubmed/17744895.

Umlauf, L. and H. Burchard, 2003: A generic length-scale equation for geophysical turbulence models. Journal of Marine Research, 61 (2), 235-265, doi:10.1357/ 002224003322005087.

Valcke, S., 2006: Oasis3 user guide (prism_2-5). PRISM support initiative report, 3, 64.

Vannière, B., E. Guilyardi, G. Madec, F. J. Doblas-Reyes, and S. Woolnough, 2013: Using seasonal hindcasts to understand the origin of the equatorial cold tongue bias in CGCMs and its impact on ENSO. Climate Dynamics, 40 (3-4), 963-981, doi: 10.1007/s00382-012-1429-6.

Vannière, B., E. Guilyardi, T. Toniazzo, G. Madec, and S. Woolnough, 2014: A systematic approach to identify the sources of tropical SST errors in coupled models using the adjustment of initialised experiments. Climate Dynamics, 43 (7-8), 2261-2282, doi:10.1007/s00382-014-2051-6, URL http://link.springer.com/ $10.1007 / \mathrm{s} 00382-014-2051-6$.

Voldoire, A., M. Claudon, G. Caniaux, H. Giordani, and R. Roehrig, 2014: Are atmospheric biases responsible for the tropical Atlantic SST biases in the CNRM-CM5 coupled model? Climate Dynamics, 43 (11), 2963-2984, doi:10.1007/s00382-013-2036-x, URL http://link. springer. com/10 .1007/s00382-013-2036-x. 
Wahl, S., M. Latif, W. Park, and N. Keenlyside, 2011: On the tropical atlantic sst warm bias in the kiel climate model. Climate Dynamics, 36 (5-6), 891-906.

Waliser, D. E. and C. Gautier, 1993: A satellite-derived climatology of the itcz. Journal of Climate, 6 (11), 2162-2174.

Wang, C., L. Zhang, S.-K. Lee, L. Wu, and C. R. Mechoso, 2014: A global perspective on cmip5 climate model biases. Nature Climate Change, 4 (3), 201-205.

Weingartner, T. J. and R. H. Weisberg, 1991: On the annual cycle of equatorial upwelling in the central atlantic ocean. Journal of Physical Oceanography, 21 (1), 68-82.

Wyant, M., C. Bretherton, J. Bacmeister, J. Kiehl, I. Held, M. Zhao, S. Klein, and B. Soden, 2006: A comparison of tropical cloud properties and responses in $\mathrm{gcms}$ using mid-tropospheric vertical velocity. Climate Dyn, 27, 261-279.

Xu, Z., P. Chang, I. Richter, and G. Tang, 2014a: Diagnosing southeast tropical atlantic sst and ocean circulation biases in the cmip5 ensemble. Climate dynamics, 43 (11), 3123-3145.

Xu, Z., M. Li, C. M. Patricola, and P. Chang, 2014b: Oceanic origin of southeast tropical atlantic biases. Climate dynamics, 43 (11), 2915-2930.

Zhang, M., et al., 2005: Comparing clouds and their seasonal variations in 10 atmospheric general circulation models with satellite measurements. Journal of Geophysical Research: Atmospheres, 110 (D15).

Zhang, S., 2011: A study of impacts of coupled model initial shocks and state-parameter optimization on climate predictions using a simple pycnocline prediction model. Journal of Climate, 24 (23), 6210-6226.

Zheng, Y., T. Shinoda, J.-L. Lin, and G. N. Kiladis, 2011: Sea surface temperature biases under the stratus cloud deck in the southeast pacific ocean in 19 ipcc ar4 coupled general circulation models. Journal of Climate, 24 (15), 4139-4164. 


\section{Supplementary Material}
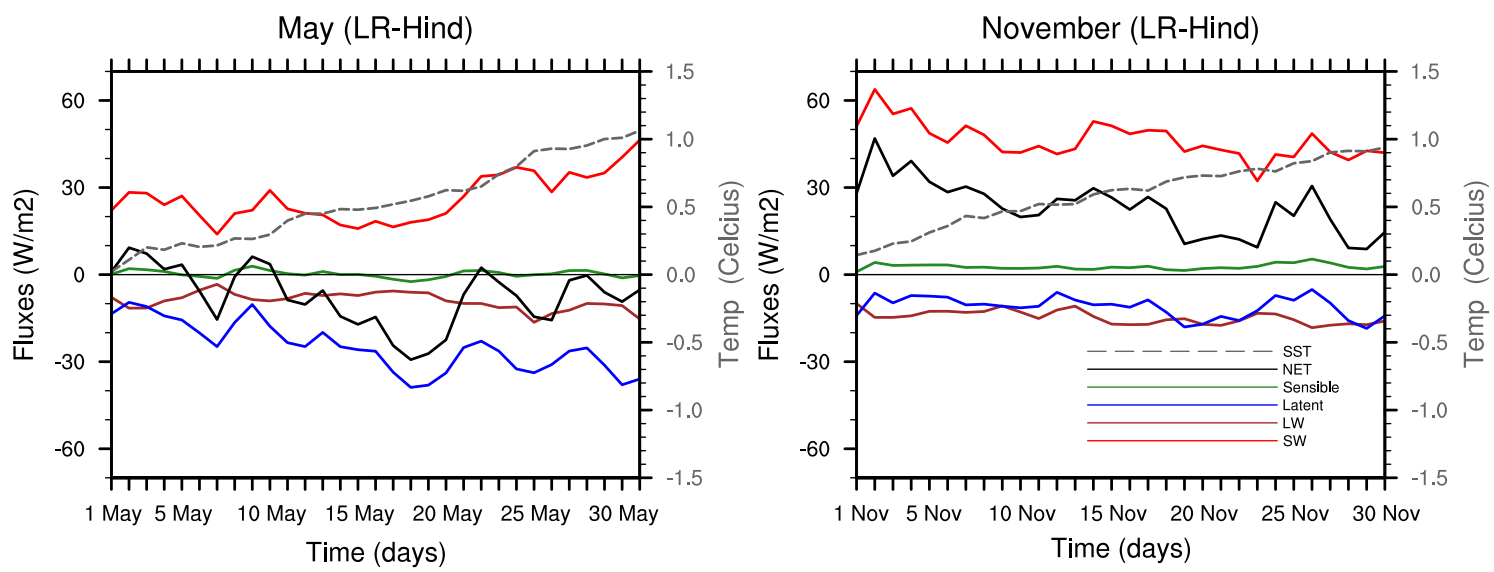

Figure S1: Forecast biases in the four components of the area-averaged surface heat fluxes over the CAB region (positive is downwards, units are $\mathrm{W} / \mathrm{m}^{2}$ ) for the LR-Hind experiment with respect to TropFlux. Sensible heat fluxes are shown in green, latent in blue, longwave in brown, shortwave in red, and net heat fluxes in black, for the the summer months (May-August) in the top row and winter months (NovemberFebruary) in the bottom row. The grey line is the SST bias (with respect to ERAi), and its values are shown in the right $\mathrm{Y}$ axis, in ${ }^{\circ} \mathrm{C}$. The biases are calculated as the difference between LR-Hind and the reference dataset (TropFlux or ERAi) in their time mean data over 17 years (1993-2009) for each day in May (left) and November (right).
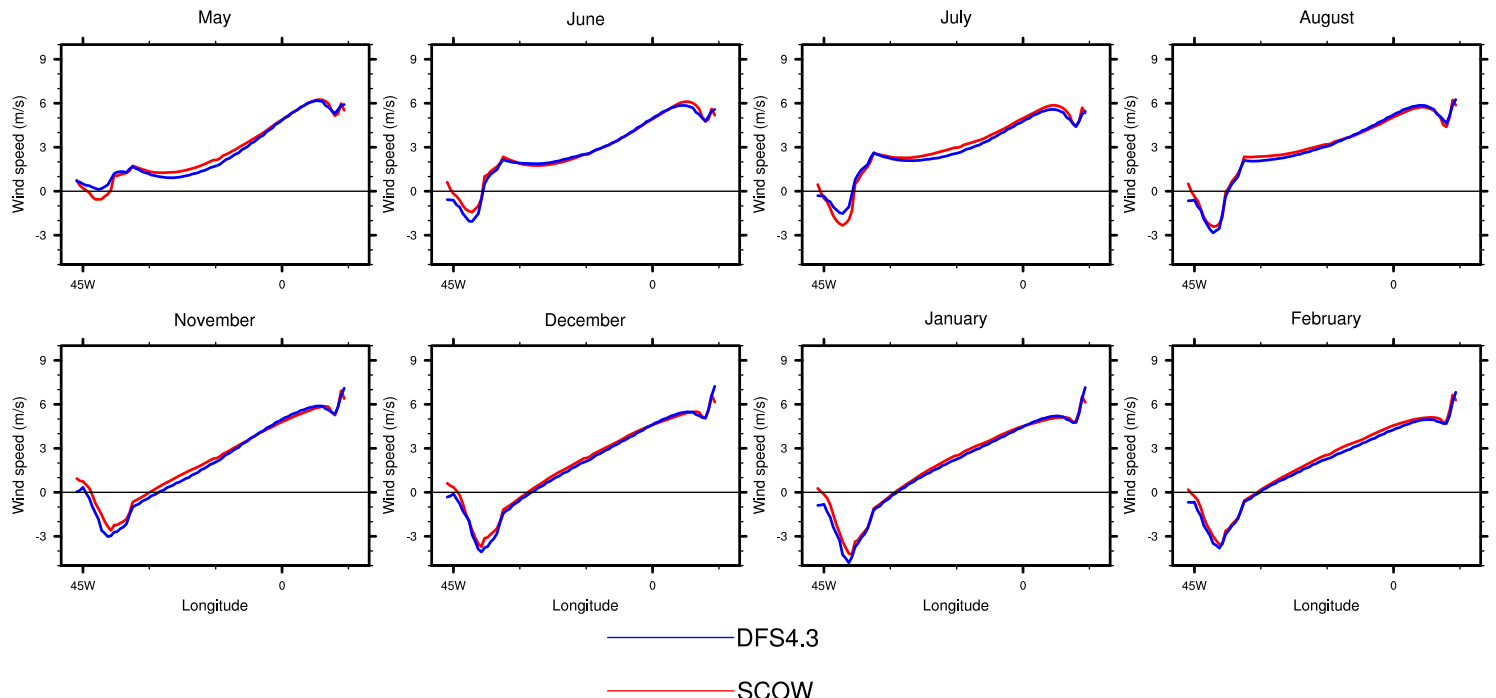

Figure S2: Climatological meridional surface wind speed vas (in m/s, time averages between 1999-2009), and zonally averaged between $25^{\circ} \mathrm{S}-5^{\circ} \mathrm{S}$, for DFS4.3 and QuikSCAT. 


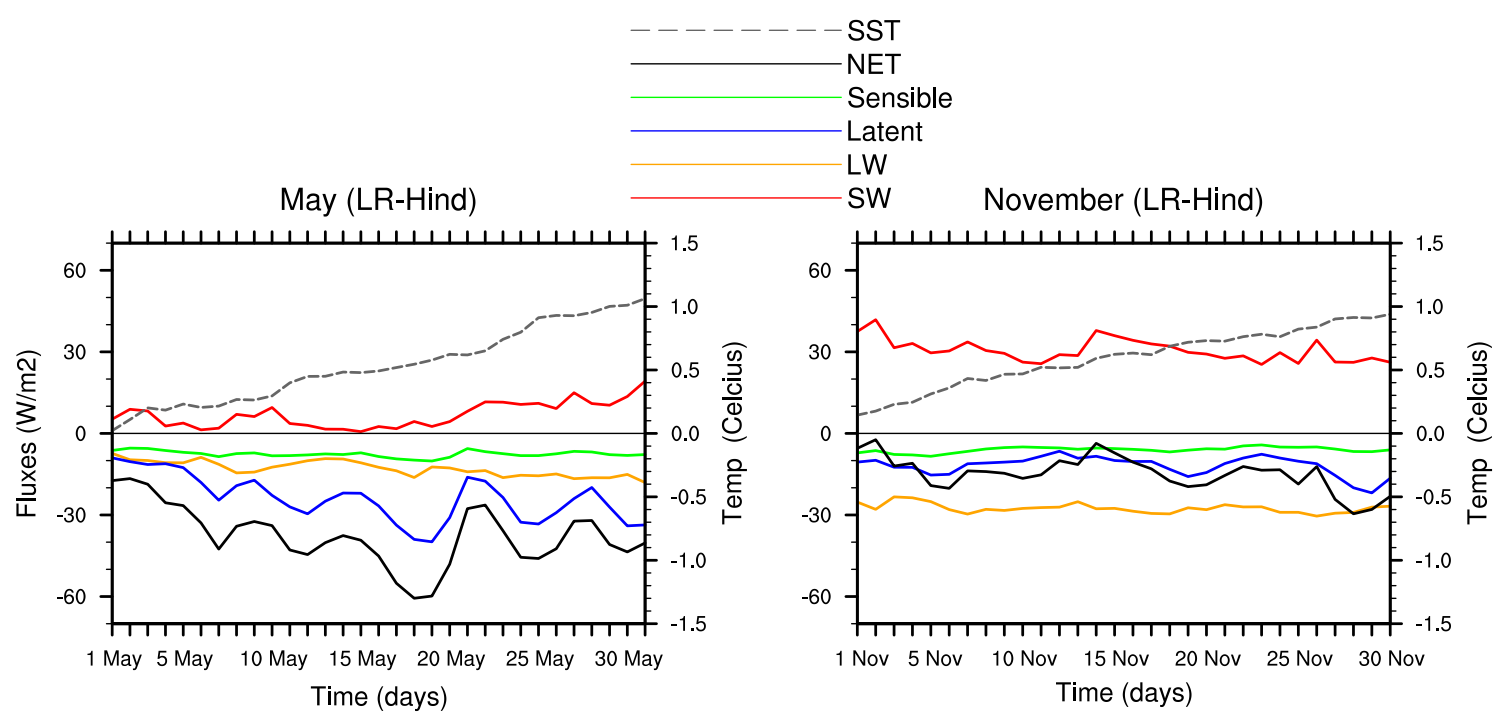

Figure S3: Forecast biases in the four components of the meridionally averaged (between $18^{\circ} \mathrm{S}-5^{\circ} \mathrm{S}$ ) surface heat fluxes (positive is downwards, units are $\mathrm{W} / \mathrm{m}^{2}$ ) for the LR-Hind experiment with respect to OAFlux (as in Fig 15). 